\title{
Inhibition of Copper Corrosion by Rice Straw Extract in 2M Solution of Nitric Acid
}

\author{
Mahmoud I. El-Tantawy ${ }^{1}$, Hend S. Gadow ${ }^{2}$, Ibrahim G. Rashed ${ }^{1}$, Abd El-Aziz S.Fouda 3,*(D) \\ 1 Engineering technology and environmental management, Faculty of Engineering, Mansoura University, Egypt \\ 2 Higher Institute for Engineering and Technology, New Damietta, Egypt; hsgado73@gmail.com (H.S.G.); \\ 3 Department of Chemistry, Faculty of Science, El-Mansoura University, Egypt; asfouda@mans.edu.eg (A.E-A.S.F.); \\ * Correspondence: asfouda@mans.edu.eg (A.E-A.S.F.);
}

Scopus Author ID 56231506400

Received: 8.03.2021; Revised: 8.04.2021; Accepted: 11.04.2021; Published: 19.04.2021

\begin{abstract}
In our research, the rice straw extract was utilized as an eco-friendly green inhibitor to prevent $\mathrm{Cu}$ dissolution in $2 \mathrm{M}$ of $\mathrm{HNO}_{3}$. Mass loss, electrochemical tests, and surface checks were utilized to demonstrate the importance of this green extract to prevent the $\mathrm{Cu}$ corrosion procedure. From all tests, one can find that with increasing the dose of rice straw extract (up to $300 \mathrm{ppm}$ ), the protection efficacy increased to $96.8 \%$ at $25^{\circ} \mathrm{C}$. Polarization curves showed that rice straw extract is a mixed-kind inhibitor that retards the anodic and cathodic reactions. From the EIS examination, the double-layer capacitance lowered by improving the dose of rice straw extract was noticed. On the other hand, the charge transfer resistance was improved. The corrosion protection (\% I) of $\mathrm{Cu}$ occurs by the adsorption procedure, and this metal is followed by the Flory-Huggins and Langmuir adsorption isotherms. From both isotherms, the adsorption parameters were deduced. This test was also applied at different temperatures, and the activated parameters were determined and discussed. Results gotten from all used tests are in excellent harmony.
\end{abstract}

Keywords: corrosion inhibition; copper; $\mathrm{HNO}_{3}$, rice straw extract; Langmuir isotherm.

(C) 2021 by the authors. This article is an open-access article distributed under the terms and conditions of the Creative Commons Attribution (CC BY) license (https://creativecommons.org/licenses/by/4.0/).

\section{Introduction}

In Earth's crust, copper is the third most widely abundant element, accounting for about eight percent of the mineral components [1,2]. The importance of $\mathrm{Cu}$ metal and its alloys is due to its multiple applications in several industries, such as the food industry, electronic devices, building, transport, etc. [3,4]. These different applications depend on several reasons as their low price, their high energy density, and their electrical capacity. Copper metal can form a thin stable oxide layer on it, but in the case of aggressive media as $\mathrm{HNO}_{3}$, this oxide layer is destroyed, and the corrosion for the metal begins [5-7]. Various acidic solutions such as nitric, sulfuric, and hydrochloric acids are widely utilized in many techniques such as washing boilers, pickling metals, acidification of oil wells, and recovery of an ion exchanger. $[8,9]$. In addition to the former, $\mathrm{HCl}$ is one of the acids commonly applied in improving the productivity (motivation) of wells in oil and gas production and is used over several years to increase the initial productivity of new wells as well as restore the productivity of old wells [10-17].

There are several methods to control the process of metallic corrosion. However, one of the greatest practical methods utilized is the use of inhibitors to minimize corrosion in industrial and academic studies and proven in literary surveys [18-22]. Corrosion inhibitors are 
defined as those substances that may reduce or prevent the metals' interaction with these solutions if added in small amounts to corrosive solutions. Corrosion inhibitors have many uses if applied to numerous systems like refineries, refrigeration systems, oil and gas production units, and other systems. Inhibitors are organic materials that contain heteroatoms as nitrogen, oxygen, and sulfur atoms, in addition to the many existing bonds, all of which help them to adsorb on the surface of the metal and to protect it from corrosion [23-26]. Since obtaining synthetic organic inhibitors is costly in addition to environmental damage, researchers have recently focused their efforts on replacing synthetic organic inhibitors with inhibitors that can be obtained from natural materials. Naturally, occurring corrosion inhibitors are environmentally friendly, available, inexpensive, and sources for obtaining them are renewable [27-34].

This study aims to use environmentally friendly materials as inhibitors for $\mathrm{Cu}$ corrosion in a $2 \mathrm{M} \mathrm{HNO}_{3}$ solution, and the choice was to use rice straw extract because of the following properties: it contains many organic compounds that are ideal in the procedure of hindrance the metals from corrosion as well as low cost and accessibility. Also, its presence causes problems such as pollution, which in turn affects human health, and by using it, one can turn waste into useful materials for society. In this paper, several methods have been used to study the inhibition performance.

\section{Materials and methods}

\subsection{Preparations of metals.}

Through a wire machine, the copper samples used in chemical tests and surface analysis were cut into a square to avert different angularity and avoid deformation of the lattice structure caused by other methods. Their dimensions were $(20 \mathrm{~mm} \times 20 \mathrm{~mm} \times 0.2 \mathrm{~cm})$ and purchased from Naga Hamady Co, Egypt. About electrochemical corrosion, the working rods were prepared in $1 \times 1 \mathrm{~cm}^{2}$ dimensions and surrounded by a glass rod using epoxy, after welding with copper wire, and placed for 24 hours to adhere well. The samples used are mechanically sanded with different degrees of silicon carbide (320-1200) slabs until they look shiny, and by double distilled water, the sheets were washed and then wiped with acetone.

\subsection{Solutions.}

In this experiment, the nitric acid that was used $(5 \mathrm{M})$ was prepared from $70 \%$ nitric acid using dual distilled water. Afterward, its dose was checked. Using the prepared $\mathrm{HNO}_{3}$, different solutions containing $2 \mathrm{M} \mathrm{HNO}_{3}$ were prepared without adding different doses of rice straw extract ranging from 50 to $300 \mathrm{ppm}$.

\subsection{Preparation of rice straw extract.}

Rice straw used in this research was obtained from a private field in Daqahlia Governorate, Egypt. After assembly, we dried it in an oven at $60^{\circ} \mathrm{C}$. After this step, we crushed it and converted it into powder. Dried and ground rice straw was extracted using the solvent extraction method in aqueous ethanol, where the ethanol to water ratio is $60: 40$ with $0.01 \mathrm{M}$ sulfuric acid and is stirred for 12 hours at a temperature of $50-60^{\circ} \mathrm{C}$. Finally, the ethanol is vaporized until it gets a black liquid, dried in an oven to remove the rest of the ethanol and obtain the black powder used in the research [35]. 


\subsection{Chemical constituents of rice straw extract.}

The main constituents of rice straw are lignin $19.2 \%$, hemicelluloses $24.3 \%$, ash $18.85 \%$, and $3.25 \%$ other trace elements [36].

\subsection{Mass loss $(M L)$ measurements.}

All experiments with ML tests were considered by the ASTM standard [37]. The $\mathrm{Cu}$ coins are divided, washed with double distilled water, dried, weighed, and added rice straw extract from $50 \mathrm{ppm}$ to $300 \mathrm{ppm}$. This occurs in the presence of $2 \mathrm{M} \mathrm{HNO}_{3}$ for comparison with a sample that has been positioned in the solution of nitric acid without any rice straw. The steps are repeated every half hour until the end of the experiment after 3 hours. All solutions were prepared in beakers $100 \mathrm{ml}$ each time the ML is calculated using a sensitive balance. \% I and corrosion rates (C.R.) are determined according to the following equations [38]:

C.R. $($ corrosion rate $)=\Delta \mathrm{m} / \mathrm{St}$

ML is $\Delta \mathrm{m}$, the sample surface area exposed to the solution in $\mathrm{cm}^{2}$ expressed by $\mathrm{S}$, and the submersion time as $t$ in min. \% I, surface coverage $(\theta)$ using the equation (1):

$$
\% \mathrm{IE}=1-\left[\left(\mathrm{CR}_{\text {inh }}\right) /\left(\mathrm{CR}_{\text {corr }}\right)\right] \times 100=\theta \times 100
$$

\subsection{Potentiodynamic polarization (PP) investigation.}

In this research, the PP test was concluded in a cell consisting of three electrodes, copper which is utilized as the working electrode in this paper, and the exposed surface area equal $1 \mathrm{~cm}^{2}$ and before using the copper electrode, it is processed according to the method followed ML, the second electrode is the auxiliary (Pt foil), and the third is reference electrode which is saturated calomel electrode (SCE). The working electrode is placed for 30 minutes in a solution with an open circuit voltage, where the stability condition is obtained. PP curves were recorded at a rate scan of $0.2 \mathrm{mVs}^{-1}$, primarily from $-0.6 \mathrm{~V}$ to $+0.5 \mathrm{~V}$ (SCE). The \% I and $\Theta$ for rice straw extract is computed from the next Eqs. [39]:

$$
\begin{aligned}
& \mathrm{I} \%=\left[\left(\mathrm{i}_{\text {corr }}-\mathrm{i}_{\text {corr }(\operatorname{Inh})}\right) / \mathrm{i}_{\text {corr }}\right] \times 100 \\
& \theta=\left[\left(\mathrm{i}_{\text {corr }}-\mathrm{i}_{\text {corr }(\operatorname{Inh})}\right) / \mathrm{i}_{\text {corr }}\right]
\end{aligned}
$$

where $\mathrm{i}_{\text {corr }}$ and $\mathrm{i}_{\text {corr }(\mathrm{Inh})}$ is the dissolution current density values in the non-existence and existence of rice straw extract, correspondingly and specified by extrapolation of both Tafel lines to the potential of corrosion.

\subsection{Electrochemical impedance spectroscopy (EIS) measurements.}

In this test, we used the $\mathrm{AC}$ signs alternating from $100 \mathrm{kHz}$ to $0.1 \mathrm{~Hz}$ with a peak amplitude of $10 \mathrm{mV}$ at OCP. All the outcome data of EIS were utilizing the Gamry Echem program, and by utilizing the resistance for a measure of inhibition by the next Eq. [40]:

$$
\% \mathrm{I}=\left(1-\mathrm{R}_{\mathrm{ct}} / \mathrm{R}^{0}{ }_{\mathrm{ct}}\right) \times 100
$$

where, $\mathrm{R}_{\mathrm{ct}}$ and $R_{c t}{ }^{\circ}$ are the charge transfer resistances for the inhibited by rice straw extract and the inhibitor-free system from rice straw extract. 


\subsection{Tests of electrochemical frequency modulation (EFM).}

In our research, we used the experiment of EFM and applied the signal with a capacity of $10 \mathrm{mV}$ among two sinus waves from 2 to $5 \mathrm{~Hz}$ [41]. The Current density of (icorr), (CF2 and $\mathrm{CF} 3)$, and ( $\beta_{\mathrm{a}}$ and $\beta_{\mathrm{c}}$ ) were calculated from the maximum peaks [42].

In all electrochemical investigations, the device used was Gamry Potentiostat / Galvanostat / ZRA (PCI4-G750). Gamry includes the DC105, EFM140, and EIS300 programs for PP, EFM, and EIS calculation, correspondingly. Echem Analyst sort 5.5 was utilized to drawn, calculated, and synthesize value.

\subsection{Surface examinations.}

\subsubsection{Atomic force microscope (AFM) analysis.}

Using AFM, the copper surface properties were tested. AFM occurred in $2 \mathrm{M} \mathrm{HNO}_{3}$ in the lack of rice straw extract and the example of the maximum dose of rice straw extract $(500$ ppm). AFM was performed in a contact manner with a silicon nitride probe (MLCT model; Bruker).

\subsubsection{X-ray photoelectron spectroscopy (XPS) examination.}

In this study, the morphology of copper samples was verified before and later being immersed in a solution of $2 \mathrm{M} \mathrm{HNO}_{3}$ in the attendance and absence of rice straw extract (300 ppm) for three hours using electronic XPS. Amounts were made utilizing Thermo-Scientific, USA.

In this technique, $\mathrm{Al}$ coupons were handled in the same way as previous treatment coins were treated for a WL experiment.

\subsubsection{Fourier-transform infrared spectroscopy (FTIR) investigation.}

To investigate the functional groups' existence in rice straw after appending it at a dose of $300 \mathrm{ppm}$ in $2 \mathrm{M}$ nitric acid without dipping the $\mathrm{Cu}$ metal coupon and with the same dose in $2 \mathrm{M} \mathrm{HNO}_{3}$ after dipping the Cu metal 3 hours, and FTIR test utilized concluded (FT/IR-4100).

\section{Results and discussion}

\subsection{ML measurements.}

ML is an important method in determining the inhibitor efficacy of $\mathrm{Cu}$ metal corrosion, and experiments were conducted at several doses of rice straw extract in $2 \mathrm{M} \mathrm{HNO}_{3}$. The whole experience took three hours. Experiments were conducted at different temperatures $\left(25-55^{\circ} \mathrm{C}\right)$. We find this with an increased dose of rice straw to $300 \mathrm{ppm}$, the rate of inhibition increases in contrast to the rate of corrosion, which decreases with increasing dose of rice straw extract. By raising the medium's temperature, the \% I will be decreased, while there is a direct correlation between temperature and the corrosion rate (Figures 1 and 2). The increased inhibition of corrosion with an increased dose of rice straw extract can be attributed to forming a layer of the extract on the $\mathrm{Cu}$ surface by adsorption [43]. Although the effect of temperature on metals' reaction in acids is complicated [44] because of several variations to the Cu's surface (rapid etching, molecules desorption, etc.), a lower in the \% I with an improved temperature may be possible due to improved desorption. 
Table 1. Data of ML of $\mathrm{Cu}$ in 2 molar nitric acid solution for several doses of rice straw at 90 minutes and at $\left(25,35^{\circ} \mathrm{C}\right)$.

\begin{tabular}{|c|c|c|c|c|c|c|c|c|}
\hline \multicolumn{5}{|c|}{$25^{\circ} \mathrm{C}$} & \multicolumn{4}{|c|}{$3^{\circ} \mathrm{C}$} \\
\hline $\begin{array}{c}\text { Conc., } \\
\text { ppm }\end{array}$ & $\begin{array}{c}\Delta W \\
\mathrm{mg} \mathrm{cm}^{-2}\end{array}$ & $\theta$ & $\%$ IE & $\begin{array}{c}\text { C.R., } \\
\text { mg } \text { cm }^{-2} \text { min }^{-1}\end{array}$ & $\begin{array}{c}\Delta \mathrm{W}, \\
\mathrm{mg} \mathrm{cm}^{-2}\end{array}$ & $\theta$ & $\%$ IE & $\begin{array}{l}\text { C.R., } \\
\text { mg } \text { cm }^{-2} \text { min }^{-1}\end{array}$ \\
\hline Blank & 16.84 & ----- & ----- & 0.187 & 27.48 & ----- & ----- & 0.309 \\
\hline 50 & 1.290 & 0.920 & 92.0 & 0.0143 & 7.63 & 0.722 & 72.2 & 0.084 \\
\hline 100 & 1.17 & 0.930 & 93.0 & 0.013 & 7.06 & 0.743 & 74.3 & 0.078 \\
\hline 150 & 0.65 & 0.961 & 96.1 & 0.007 & 6.32 & 0.770 & 77.0 & 0.070 \\
\hline 200 & 0.64 & 0.962 & 96.2 & 0.007 & 5.63 & 0.795 & 79.5 & 0.063 \\
\hline 250 & 0.61 & 0.964 & 96.4 & 0.006 & 4.61 & 0.832 & 83.2 & 0.051 \\
\hline 300 & 0.46 & 0.973 & 97.3 & 0.005 & 4.19 & 0.849 & 84.9 & 0.046 \\
\hline
\end{tabular}

Table 2. Data of ML of $\mathrm{Cu}$ in 2 molar nitric acid solution for several doses of rice straw at 90 minutes and at

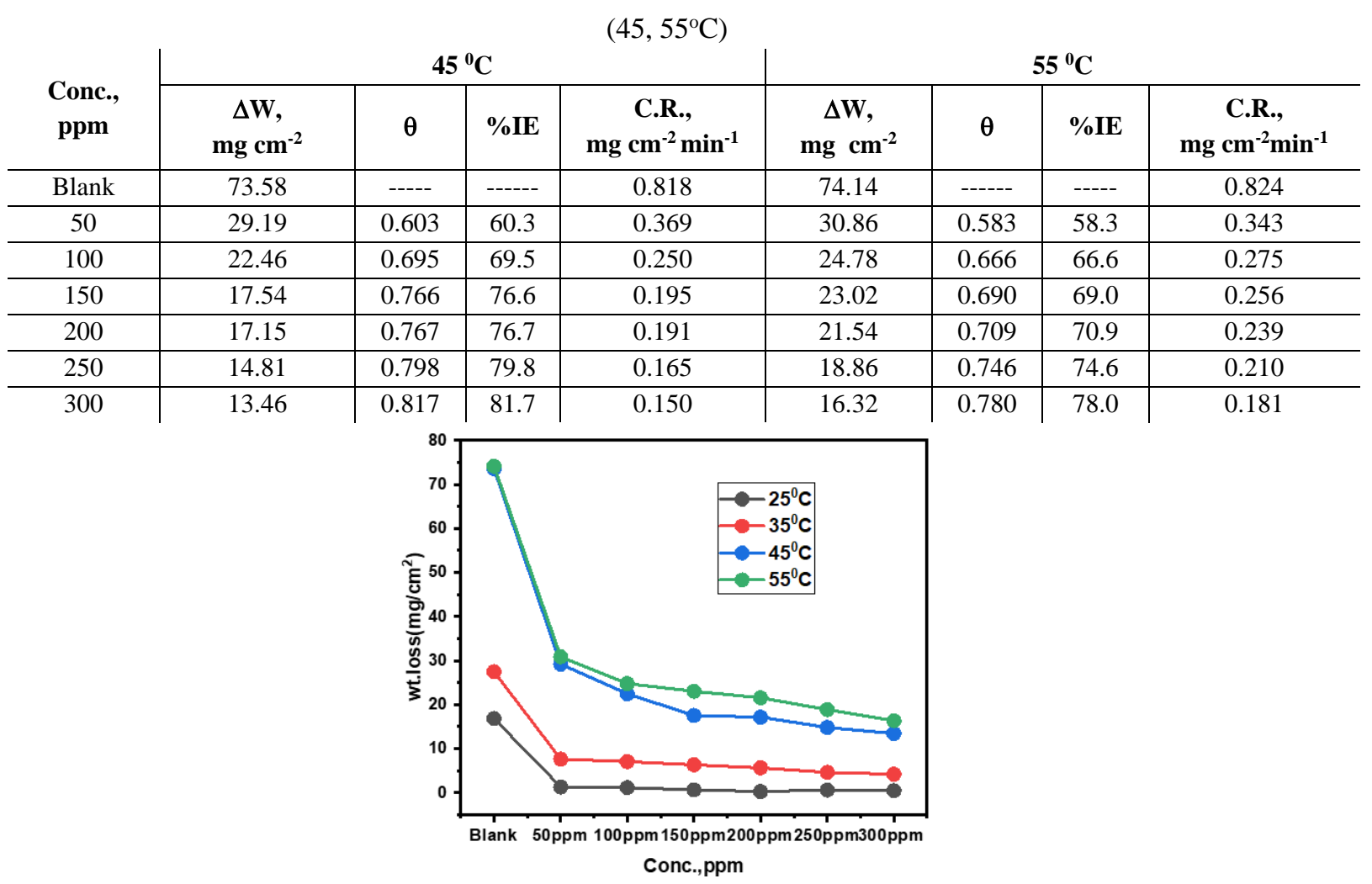

Figure 1. The effect of adding different doses from rice straw extract on the corrosion rate of $\mathrm{Cu}$ metal.

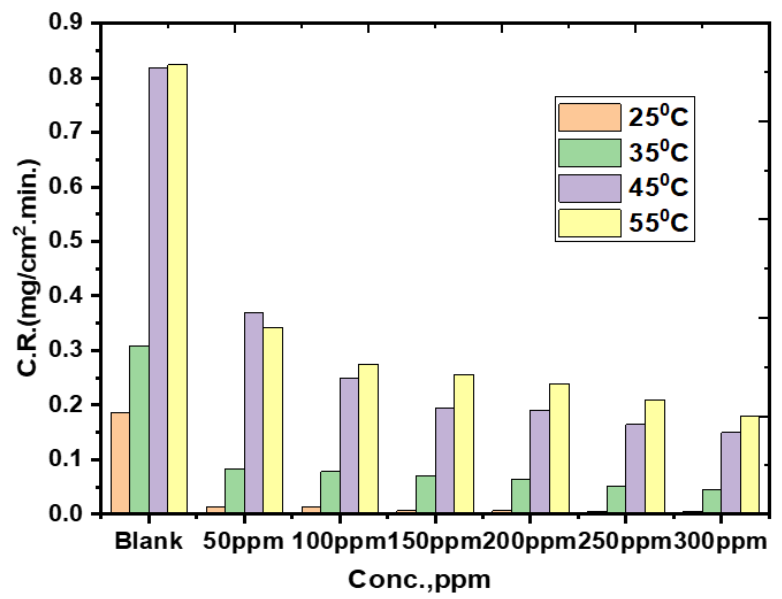

Figure 2. The outcome of addition of several doses from rice straw extract on the $\% \mathrm{I}$ of $\mathrm{Cu}$ metal.

In this examination, the effect of temperature on the corrosion of $\mathrm{Cu}$ coins utilized in the examination and immersed in $\mathrm{HNO}_{3}$ in the non-existence and existence of altered doses from the extract of rice straw was examined. It has been found that the C.R. increases with 
increasing temperature. On the contrary, increasing the dose reduces the C.R. at one temperature, thus increasing the rate of \% I. Table (3) shows the effect of temperature on activation parameters without and with straw extract in the temperature range used. The table shows the $\mathrm{Cu}$ activation energy $\left(\mathrm{E}^{*}{ }_{\mathrm{a}}\right)$ measured via the Arrhenius formula:

$$
\text { Log Corrosion rate (C.R.) }=\log \mathrm{A}-\mathrm{E}^{*} \mathrm{a} / 2.303 \mathrm{RT}
$$

The universal gas constant was expressed using the symbol R, while the symbol (A) was used for the term exponential factor of Arrhenius, and as usual, it is used to express absolute temperatures [45]. Arrhenius diagrams are illustrated in Figure 3. Using the transitional state equation, the changes in entropy and enthalpy were calculated from the next equation [46]:

$$
\log (\mathrm{C} . \mathrm{R} / \mathrm{T})=\left[\log (\mathrm{R} / \mathrm{Nh})+\Delta \mathrm{S}^{*}{ }_{\mathrm{a}} / 2.303 \mathrm{R}\right]-\Delta \mathrm{H}^{*}{ }_{\mathrm{a}} / 2.303 \mathrm{RT}
$$

where, (h) is Planck's constant, and character (N) gives the number of Avogadro. Figure 4 shows straight lines resulting from a drawing $\log (\mathrm{C} . \mathrm{R} / \mathrm{T})$ with 1000/T, where this figure shows the transitional state of the rice straw extract. The analysis of the results was obtained in Table 3. From Table 3, there is an increase in the $\mathrm{E}_{\mathrm{a}}^{*}$ by improving the dose of rice straw extract. This improvement is due to the adsorption nature of rice straw extract on the $\mathrm{Cu}$ surface and corresponds to the physical adsorption of rice straw extract components on the $\mathrm{Cu}$ surface [47]. The results in Table 3 also showed that entropy values are negative in the existence of rice straw extract at the activated state. We conclude from this that the complex formation prefers association rather than dissociation [48]. The enthalpy values are negative, which in turn designates that the reaction that happens in the termination procedure is exothermic, and it is recognized that they can be applied to chemical and physical absorption.

Table 3. Kinetic data got from the Arrhenius equation and transition state equation.

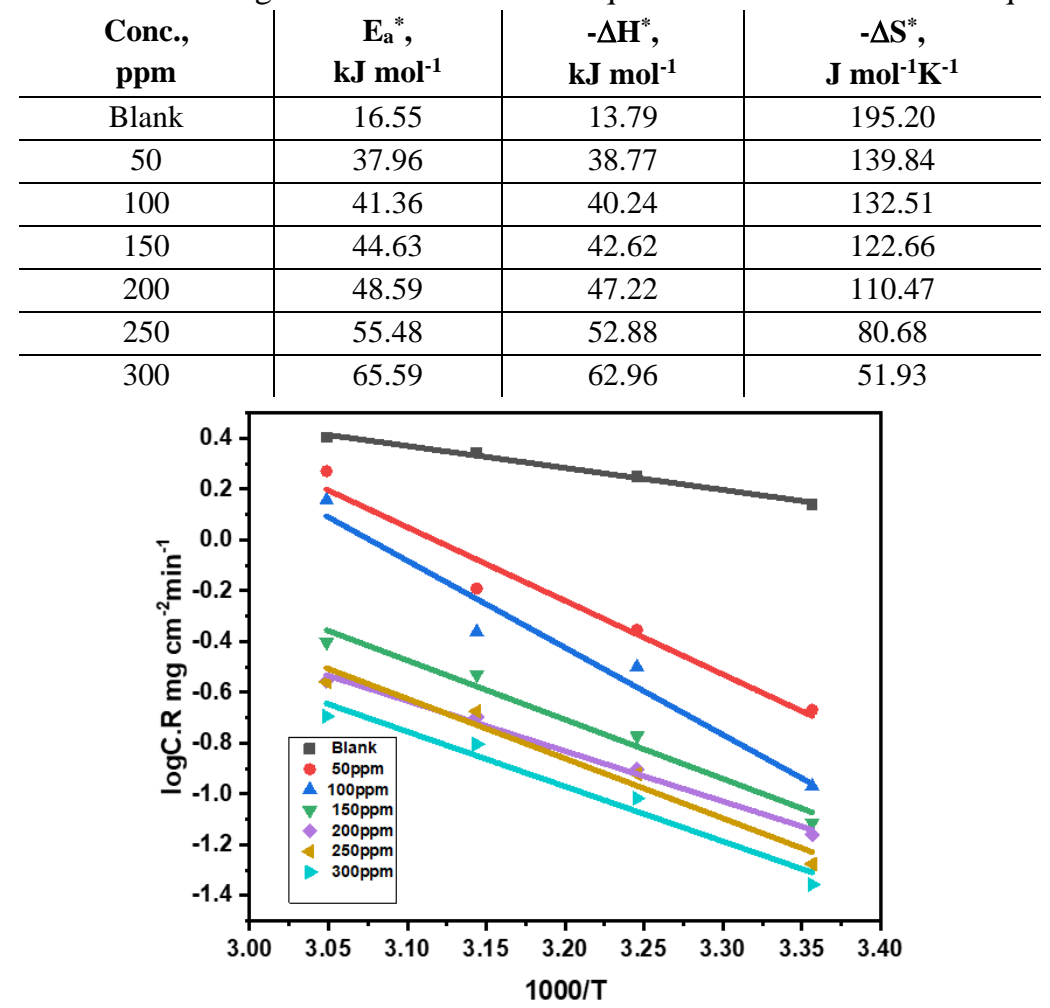

Figure 3. Arrhenius charts ( $\log$ C.R vs. 1/T) for $\mathrm{Cu}$ in 2 molars nitric acid in the non-existence and the existence changed doses of rice straw extract. 


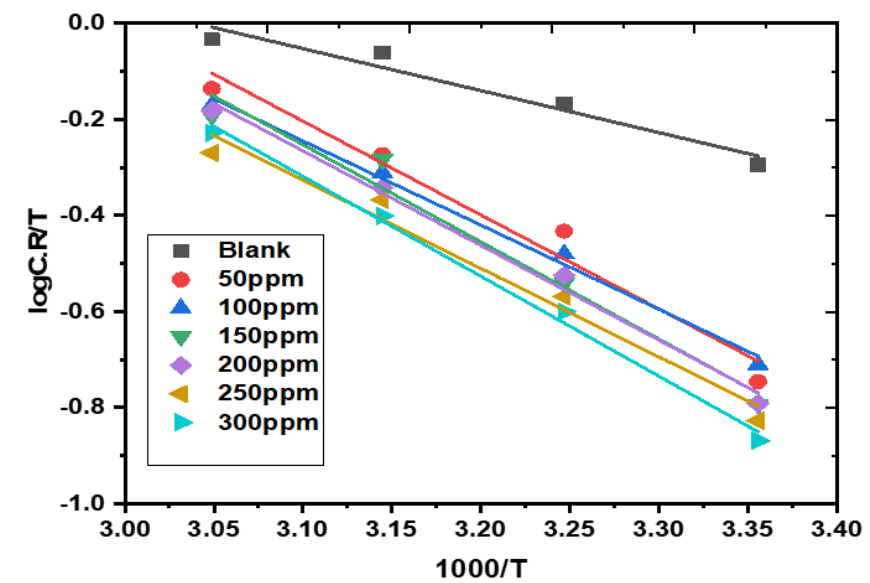

Figure 4. Charts of $\log \mathrm{C} . \mathrm{R} / \mathrm{T}$ vs. 1000/T for $\mathrm{Cu}$ in $2 \mathrm{M}$ nitric acid in the non-existence and the existence of changed doses of rice straw extract at $25^{\circ} \mathrm{C}$.

\subsection{Adsorption isotherms.}

The outcomes obtained indicate that the components of rice straw extract produced the inhibition of corrosion. From the three types of adsorption, one or more may occur: $\pi$ bonding, chemical adsorption, and physical adsorption [49]. In common, the adsorption process increases if the extract components contain hetero- atoms like sulfur, nitrogen, and oxygen where these atoms give one pair of electrons which leads to electrostatic adsorption on the $\mathrm{Cu}$ surface, forming an insoluble layer that reduces the dissolution of $\mathrm{Cu}$. Through the appropriate isothermal process, the adsorption situation of rice straw extract can be detected on the $\mathrm{Cu}$ surface. Data for ML experiments were used at different temperatures, and they were prepared in various mathematical adsorption isotherm expressions to identify the more suitable adsorption isotherms [50]. From this study for different adsorption isotherms, the more suitable adsorption isotherms for rice straw extract were Langmuir and Flory-Huggins isotherms equations 8, 9, respectively and as represented in Figures 5 and 6:

$$
\begin{aligned}
& C / \theta=1 / K_{a d s}+C \\
& \log \theta / C=\log x K_{a d s}+x \log (1-\theta)
\end{aligned}
$$

In these equations, the symbols $\mathrm{C}, \theta, \mathrm{K}_{\mathrm{ads}}$ express the dose, surface coverage, and equilibrium constant of the adsorption process, respectively. When the data of $\mathrm{x}$ is less than unity, demonstrating that a single inhibitor molecule replaces more than one water molecule, the data of the $\mathrm{R}^{2}$ for the Langmuir and Flory- Huggins isotherm was more accurate than the typical isotherm due to it is near to the unit. In Table 4, the symbol $\mathrm{K}_{\text {ads }}$ shows the molecular strength of the adsorbed layer as its high value indicates the strength of adsorption. From the table, the value of the adsorption equilibrium constant decreases with increasing temperature, indicating that the adsorption strength is higher at lower temperatures [51]. In our research, free energy was used to study the interaction of rice straw extract molecules, and this was done using the following Eq.:

$$
\Delta \mathrm{G}_{\mathrm{ads}}^{0}=-\mathrm{RT} \ln \left(55.5 \mathrm{x} \mathrm{K}_{\mathrm{ads}}\right)
$$

In this equation, the number 55.5 reveals the water dose in the bulk solution where it is given in $\mathrm{M} / \mathrm{L}$ [52]. Table 4 demonstrates the adsorption parameters for the gotten rice straw extract. The -ve values of $\Delta \mathrm{G}^{0}$ ads indicate the stability of the adsorbed layer on the metal surface 
and the extent of the adsorption process's spontaneity. From our previous knowledge, we know that the results obtained from free energy approve that the type of adsorption incident is physical adsorption and not chemisorption. It is recognized that negative values when they are less than $-20 \mathrm{~kJ} / \mathrm{mol}$ are physical adsorption and this corresponds to the results obtained. Where these results demonstrate that the adsorption is mainly physisorption. Thus, when negative values are greater than $-40 \mathrm{~kJ} / \mathrm{mol}$, adsorption is chemical adsorption [53], and this does not match the study presented. Using the subsequent equation, the change of the adsorption enthalpy was determined $\left(-\Delta \mathrm{H}^{0}\right.$ ads $)$ and the entropy value was specified $\left(-\Delta \mathrm{S}^{0}\right.$ ads):

$$
\Delta G_{\text {ads }}^{0}=\Delta H_{\text {ads }}^{0}-T \Delta S_{\text {ads }}^{0}
$$

By plotting $\Delta G^{0}$ ads versus $\mathrm{T}$ to obtain these values (enthalpy through intercept and entropy through the slope) Figure 7, from the outcome data we obtained, note that the $\Delta S^{0}$ ads is negative, which refers to exothermic. The exothermic procedure can mention physical or chemical adsorption. Note that the enthalpy values are fewer than $100 \mathrm{~kJ} / \mathrm{mol}$, demonstrating that the adsorption is chiefly physical [54].

Table 4. Langmuir parameters for adsorption of rice straw extract on the $\mathrm{Cu}$ surface at different temperatures.

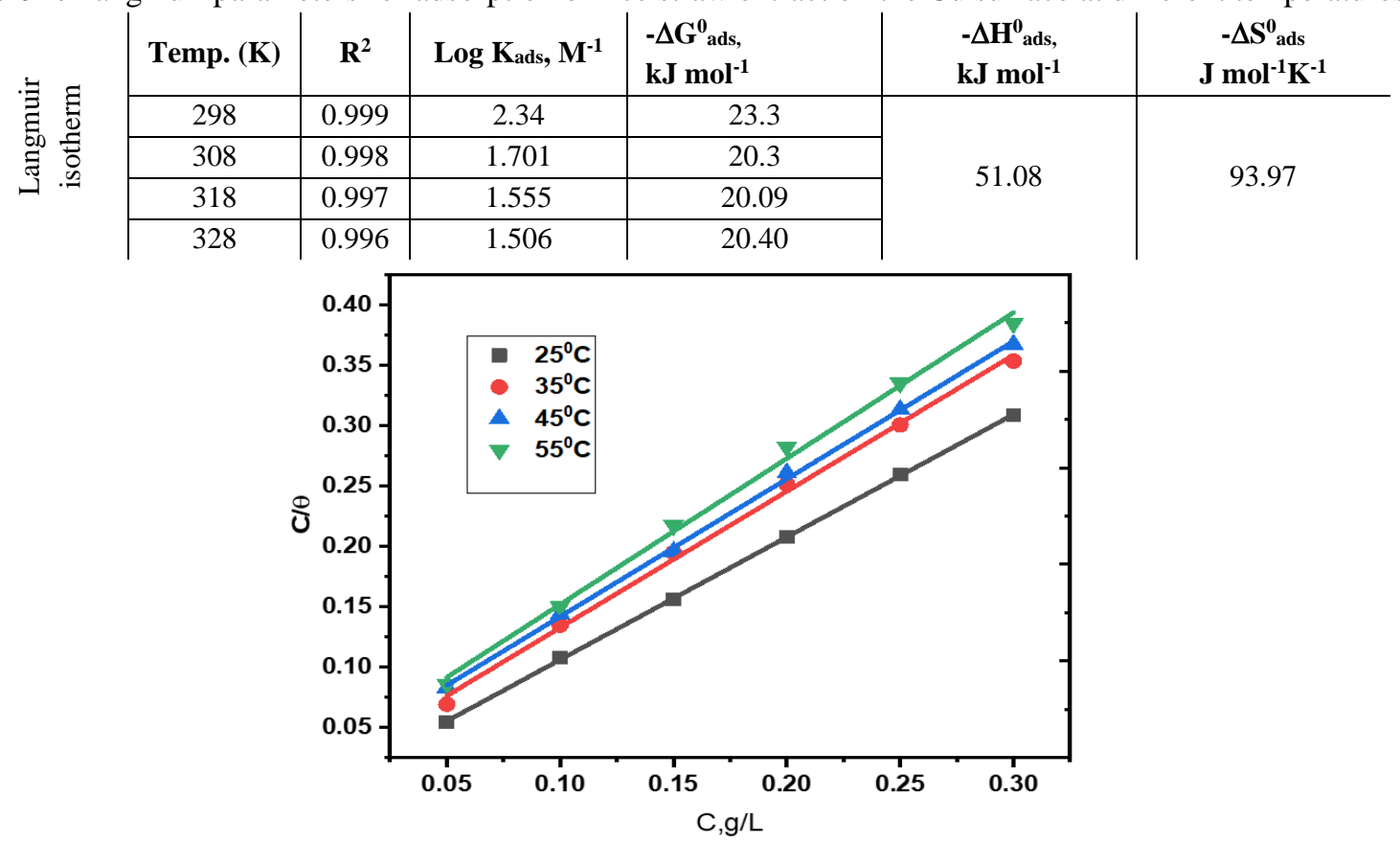

Figure 5. Langmuir of extract from rice straw adsorption on $\mathrm{Cu}$ surface in solution from $2 \mathrm{M}$ nitric acid.

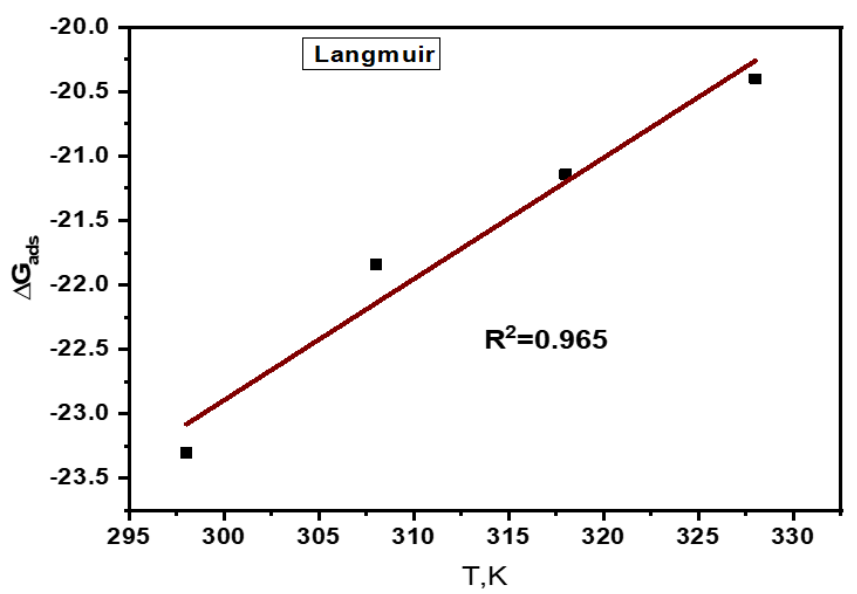

Figure 6. Effect of different temperatures on the free energies of Langmuir isotherm. 


\subsection{Open circuit potential $\left(E_{\text {ocp }}\right)$.}

Before the electrochemical study (EIS, EFM, and PP studies), graphs of the immersion time versus open circuit potential were documented for the different doses of rice straw extract when $\mathrm{Cu}$ undergoes nitric acid medium (Figure 7). The study showed that the corrosion potential tends to the noblest direction in the existence of altered doses of rice straw extract. The displacement increases to the positive direction by increasing the dose until the corrosion potential reaches stability after a period. This designates that the kinetics of the anode reaction of $\mathrm{Cu}$ in the existence of nitric acid has been strongly affected by the presence of rice straw extract [55].

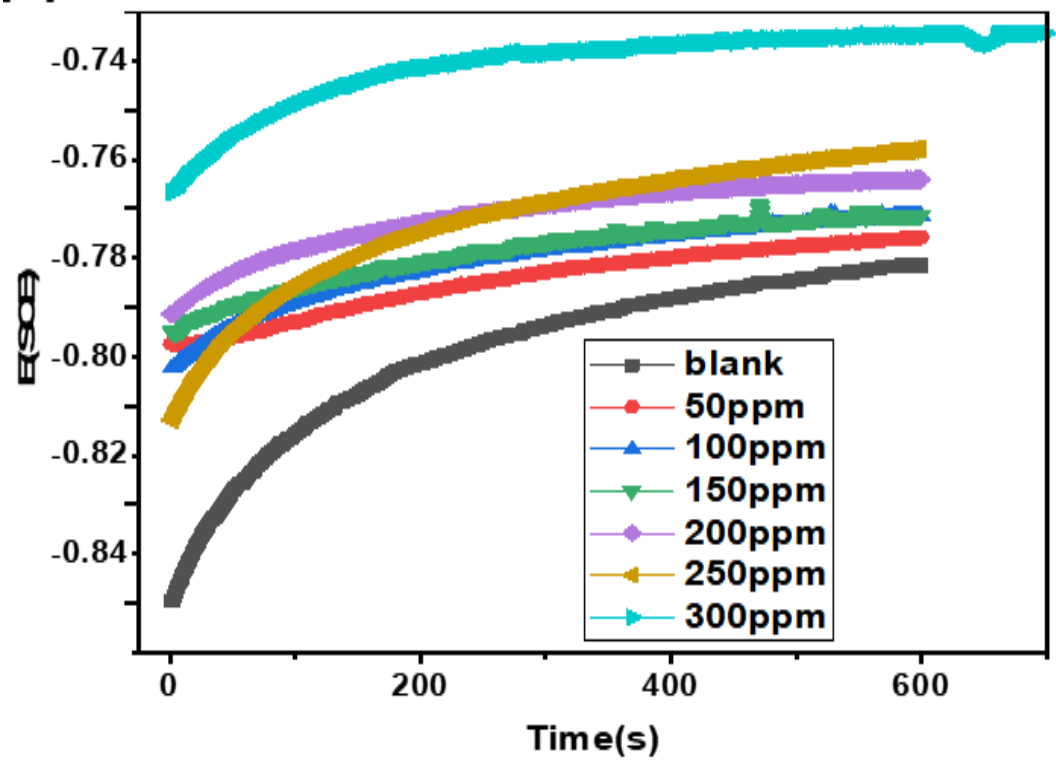

Figure 7. Potential-time curves for $\mathrm{Cu}$ in $2 \mathrm{M}$ nitric acid in the non-existence and the existence of changed doses from rice straw extract at $25^{\circ} \mathrm{C}$.

\subsection{Potentiodynamic polarization (PP) tests.}

Through the PP technology, one can obtain important data that provide information about the kinetics of the cathodic and anode reaction [4]. Through the $\mathrm{Cu}$ Tafel polarization curves dipping into $2 \mathrm{M}$ nitric acid in the presence and absence of various doses of rice straw extract, the following parameters were obtained: electrochemical corrosion, corrosion potential, and cathodic and Tafel anode constants, which given by the symbols $i_{\text {corr }}, E_{c o r r}, \beta_{c}$, and $\beta_{\mathrm{a}}$ respectively. From the values in Table 5, in the presence of different doses of rice straw extract, there is a decrease in the current density, and the decrease increases with increasing dose, indicating the formation of a layer from extract on the $\mathrm{Cu}$ surface. Moreover, the cathode and anode Tafel slopes' values have no sharp difference in the existence of altered doses from rice straw extract (Figure 8). This can be explained by the fact that the dissolution procedure is caused by covering the active sites located on the metal's surface. This indicates a dissolution mechanism that is not affected by the presence of rice straw extract [56]. If the variation in corrosion potential ( $E_{\text {corr }}$ ) values is more than $\pm 85 \mathrm{mV}$ in the presence and absence of rice straw molecules, the inhibitor molecules are named anodic or cathodic type, and this did not happen because the potential of corrosion values displacement fewer than $\pm 85 \mathrm{mV}$ [57]. The difference in $E_{\text {corr }}$ values is small $(41 \mathrm{mV})$, and this assured that the molecules of rice straw extract work as a mixed type of inhibitor [58]. Finally, from Table 5 we can conclude that as the dose of rice straw extract rises, the density of the current decreases, the \%IE increase, the corrosion rate is reduced, and the polarization resistance rises (Figure 8). 
Table 5. PP parameters for $\mathrm{Cu}$ corrosion in 2 molars nitric acid in the non-existence and the existence of changed doses of rice straw at $25^{\circ} \mathrm{C}$.

\begin{tabular}{|c|c|c|c|c|c|c|c|c|}
\hline $\begin{array}{c}\text { Conc } \\
(\mathbf{p p m})\end{array}$ & $\begin{array}{c}\text {-E } \text { Corr } \\
\mathrm{mV} \text { vs SCE }\end{array}$ & $\begin{array}{c}\mathbf{i}_{\text {corr }} \\
\mu \mathrm{A} \mathrm{cm}^{-2}\end{array}$ & $\begin{array}{c}\mathbf{R P}_{\mathbf{P}} \\
\Omega\end{array}$ & $\begin{array}{c}\beta_{\mathrm{a}} \\
\mathrm{mV} \operatorname{dec}^{-1}\end{array}$ & $\begin{array}{c}\beta_{c} \\
m V \operatorname{dec}^{-1}\end{array}$ & $\begin{array}{l}\text { C.R } \\
\text { mpy }\end{array}$ & $\theta$ & $\%$ IE \\
\hline blank & 85 & 2300 & 17.1 & 391 & 71 & 69 & & \\
\hline 100 & 91 & 511 & 37.5 & 402 & 65 & 44 & 0.781 & 78.1 \\
\hline 150 & 82 & 394 & 45.4 & 479 & 61 & 38 & 0.832 & 83.2 \\
\hline 200 & 82 & 267 & 54.0 & 427 & 65 & 27 & 0.884 & 88.4 \\
\hline 250 & 87 & 163 & 56.1 & 337 & 64 & 25 & 0.927 & 92.7 \\
\hline 300 & 81 & 150 & 72.1 & 325 & 66 & 21 & 0.931 & 93.1 \\
\hline
\end{tabular}

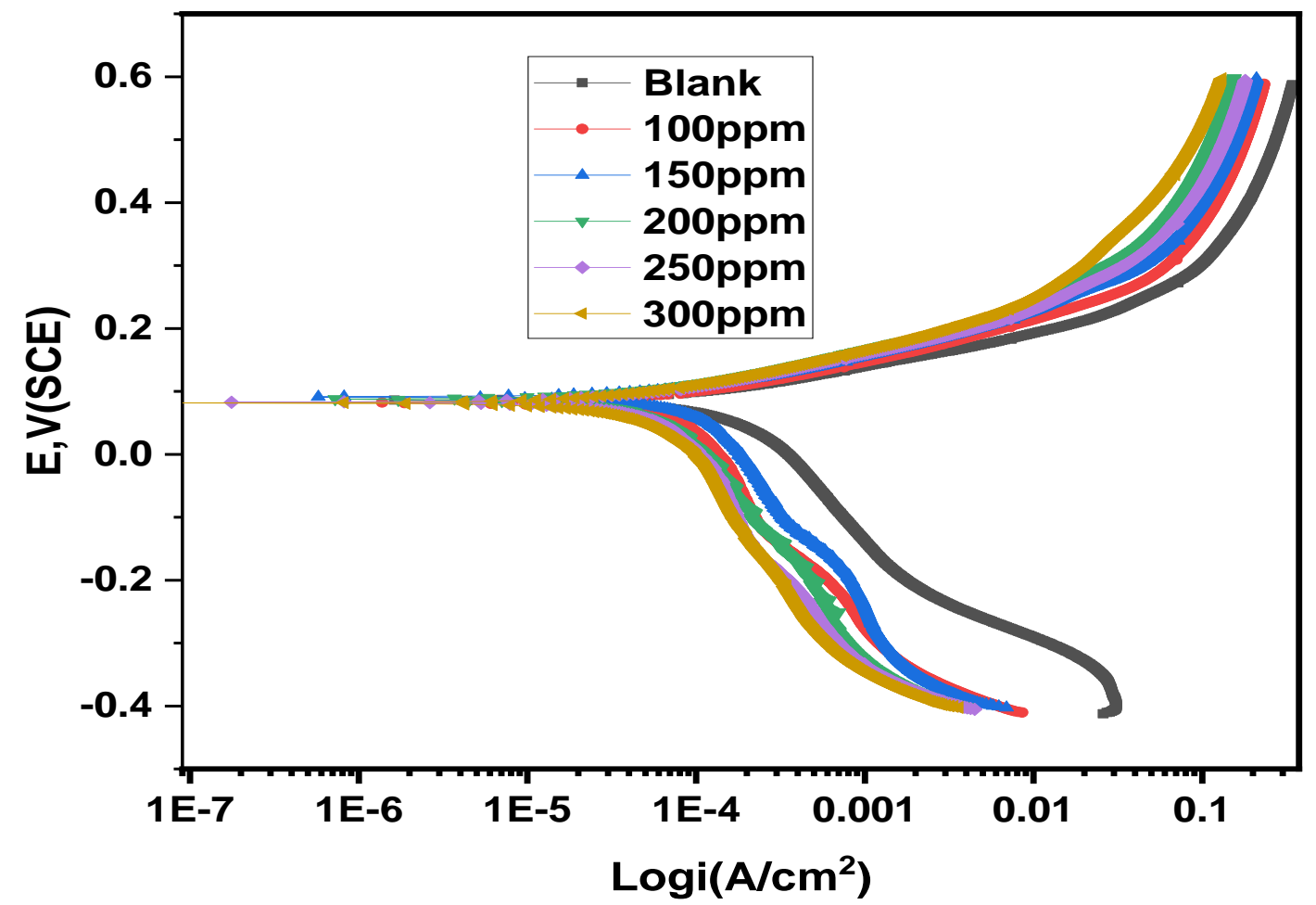

Figure 8. Plots of anodic and cathodic $\mathrm{PP}$ for $\mathrm{Cu}$ in 2 molars nitric acid in the non-existence and the existence of altered doses from rice straw extract at $25^{\circ} \mathrm{C}$.

\subsection{Study of electrochemical impedance spectroscopy (EIS) tests.}

One of the exact techniques used to check the corrosion process is EIS [59]. Figure (9) shows the impedance values of the $\mathrm{Cu}$ resulting from equivalent circuit measurements when there are different doses of rice straw extract. In this circuit, constant phase elements (CPE) are used as a substitute for capacitors to provide multiple types of homogenization that are not ideal for electrode corrosion, such as surface impurities and roughness, decreasing polishing, and grain boundaries [60]. In this study, the two parameters were used to give mathematical expressions on frequency due to the $\mathrm{Cu}$ electrode impedance dependence [61].

$$
\mathrm{Z}_{\mathrm{CPE}}=\mathrm{Y}_{0}^{-1}(\mathrm{j} \omega)^{\mathrm{n}-1}
$$

In the previous equation, the symbol Y0 is used to express the CPE parameter, and sine wave angular frequencies and the imaginary number are expressed as $\omega$ and $j^{2}=-1$, symbols, respectively. The symbol $\omega$ is equivalent to $2 \pi f$, where $f$ indicates the AC frequency. During experiments, we notice that the values of (n) ranged from 0 to 1 , and this occurs for many reasons, including surface heterogeneity, electrode roughness, and dielectric constant. The result obtained from the (n) values in $2 \mathrm{M} \mathrm{HNO}_{3}$ alone is higher than the results obtained in the existence of altered doses of rice straw extract. This may be due to the heterogeneity of the $\mathrm{Cu}$ 
surface in the presence of rice straw extract compounds [62]. From the following equation, the capacitance double-layer $(\mathrm{Cdl})$ was calculated:

$$
\mathrm{C}_{\mathrm{dl}}=\mathrm{Y}_{0} \omega^{\mathrm{n}-1} / \sin [\mathrm{n}(\pi / 2)]
$$

As a result of the charges being transported on the $\mathrm{Cu}$ surface, either near or far from the surface, multiple impedances occur due to the adsorption of anions and cations. Table (6) shows the EIS for $\mathrm{Cu}$ in $2 \mathrm{M}$ nitric acid in existence and the non-existence from different doses of rice straw extract. Nyquist and Bode charts for $\mathrm{Cu}$ without and with various doses from the extract used illustrated in Figures 10 and 11. Figure 10 demonstrates the area of small frequency in the existence of rice straw extract, the impedance data increase associated to the absence of the rice straw extract, which confirms the observed corrosion inhibition of the rice straw extract utilized. Besides, the dose of rice straw extract increases, the frequency increases, and the phase angle reaches the maximum level, indicating the effective adsorption for rice straw extract molecules on the surface of the $\mathrm{Cu}$ [63]. The deviation of the Nyquist curves from semicircles is due to the $\mathrm{Cu}$ surface's heterogeneity and the frequency dispersion [64]. By studying Table 6, we observe a decrease in $\mathrm{C}_{\mathrm{dl}}$ values as the rice straw extract dose increased. This can be explained in two ways; The first is the lower of the local dielectric constant, and the second is the rise in the thickness of the electric double layer [65]. Such is due to the adsorption of rice straw extract molecules on the $\mathrm{Cu}$ /interface of the solution. The charge transfer that mainly controls $\mathrm{Cu}$ corrosion is illustrated by impedance schemes with an almost semi-circular presence [66].

Table 6. Parameters of EIS for liquefaction of $\mathrm{Cu}$ in $\mathrm{HNO} 3$ attendance and lack of changed doses of rice straw

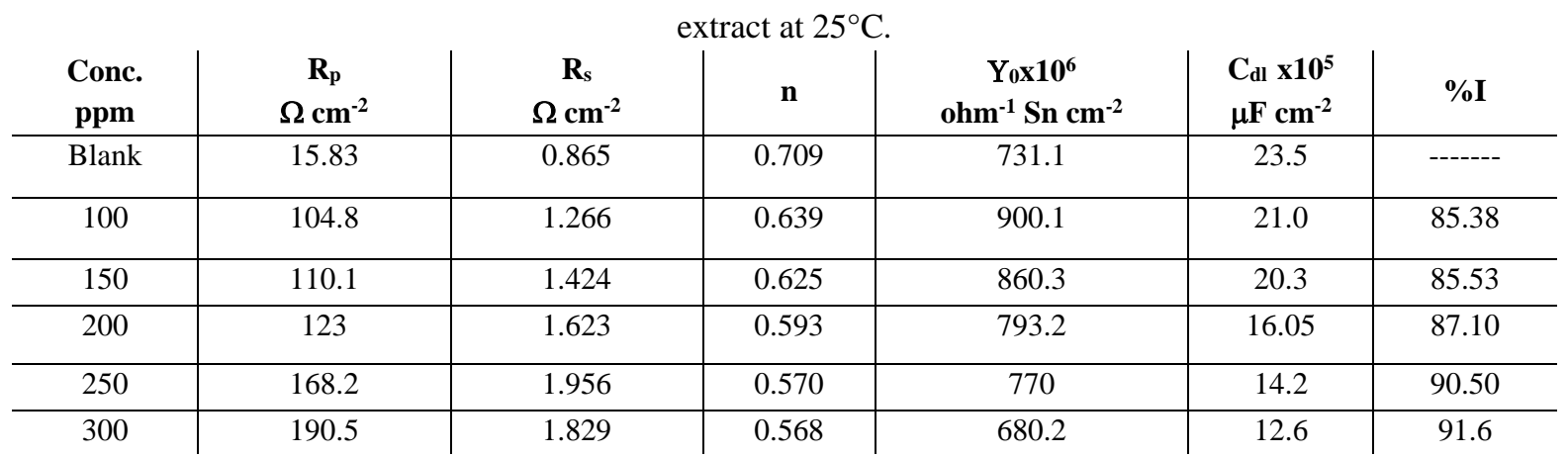

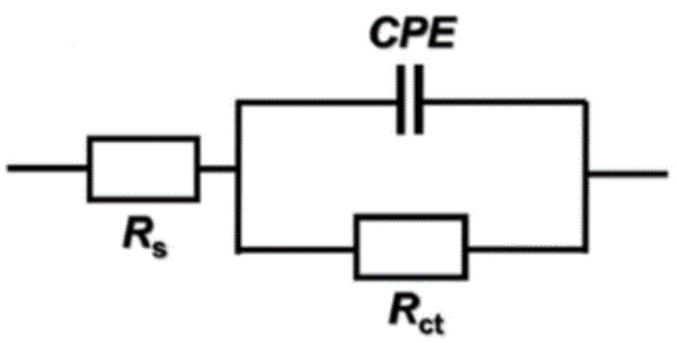

Figure 9. An equivalent circuit suggested for fitting the EIS experimental data.

3.6. Results of electrochemical frequency modulation (EFM) tests.

Figure 12 shows the EFM of $\mathrm{Cu}$ in $\mathrm{HNO}_{3}$ solution including altered doses of the extract. Because of its advantages, the EFM technique is used as a non-destructive corrosion test method. Whereas, in this way, the current corrosion values were estimated without knowing 
previous information of the Tafel slopes [67]. The electrochemical frequency modulation tests' accuracy was confirmed by an internal check of the causality factors [68].

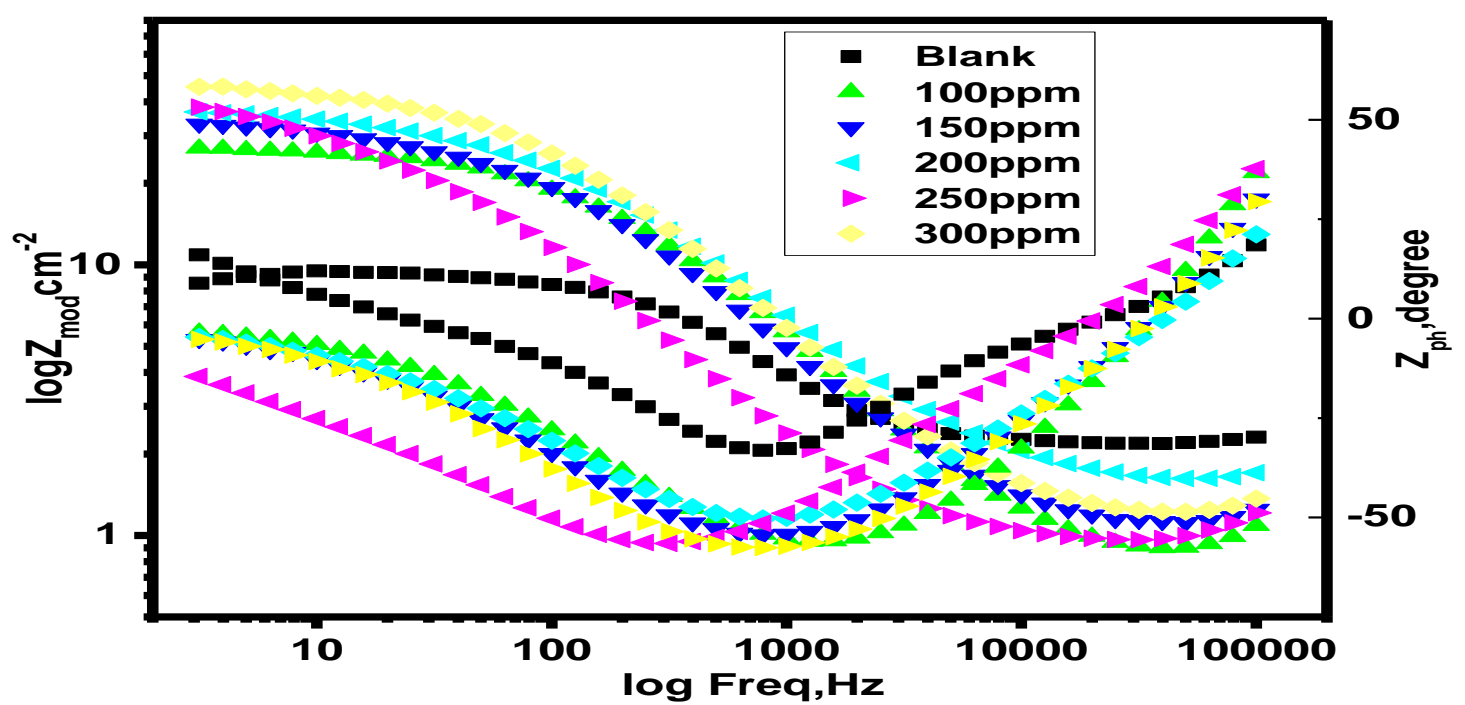

Figure 10. Bode charts for liquefaction of $\mathrm{Cu}$ in $\mathrm{HNO}_{3}$ attendance and absence of changed doses of rice straw extract at $25^{\circ} \mathrm{C}$.

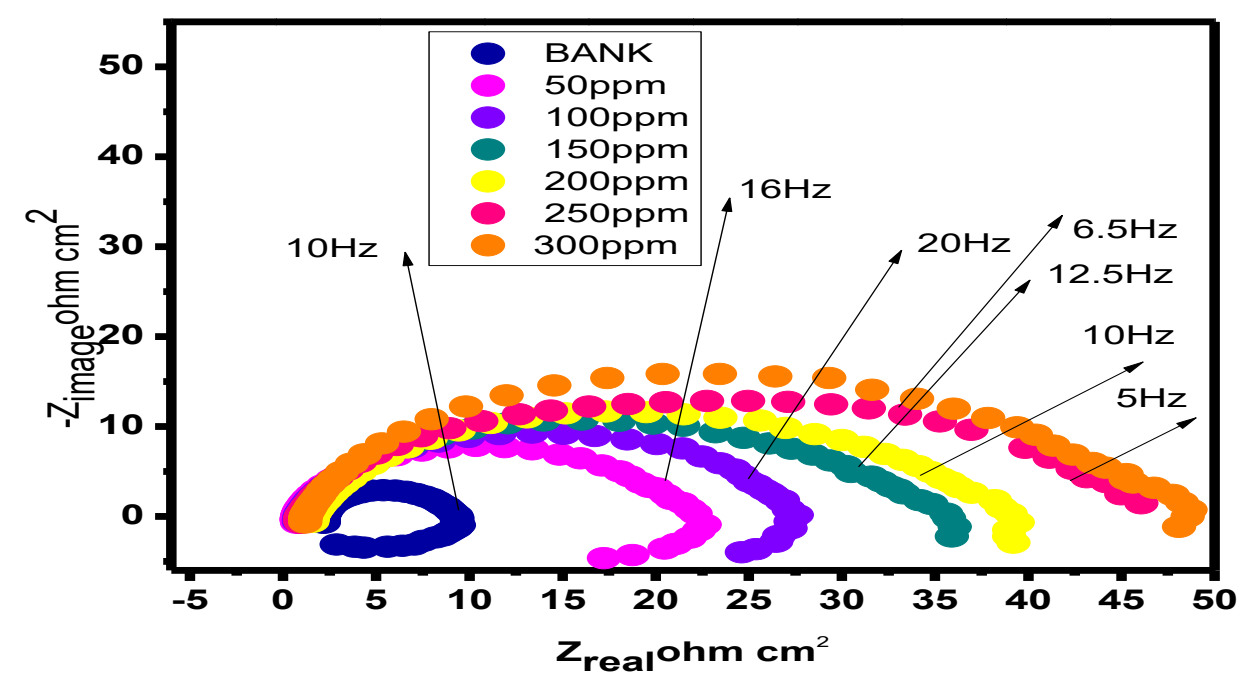

Figure 11. Nyquist charts for liquefaction of $\mathrm{Cu}$ in $\mathrm{HNO} 3$ attendance and absence of changed doses of rice straw extract at $25^{\circ} \mathrm{C}$.

The sign in this method is a little AC signal, just like the EIS test. Although the EFM method and EIS method are similar at the point mentioned above, they differ in the fact that the first method has two sine waves with variable frequencies that are used together with the cell. The system responds to potential excitation in a non-linear fashion because the current is a non-linear function of potential. The current response includes input frequencies, components of the frequency with contrast, sum, and doubles of two input frequencies. One of the conditions for determining the research's extent is that the frequencies must constitute little and integer doubles of the frequency basis. Table (7) shows the corrosion parameters. In some experiments, there may be a deviation of the standard values' causality factor values due to noise occurrence. Where values 2 and 3 are the standard values for CF-2 and CF-3, respectively. When we compared the experimental and theoretical values of causal factors, a causal relationship was found between the disorder signal and the response signal, confirming that the data are reliable $[69,70]$. The values are shown in Table 7 by increasing the dose of rice straw 
extract, the current density has a noticeable decrease, and hence \% IE increased. \%I was calculated using equation (3).

Table 7. EFM data for liquefaction of $\mathrm{Cu}$ in $\mathrm{HNO} 3$ attendance and absence of changed doses of rice straw

\begin{tabular}{|c|c|c|c|c|c|c|c|}
\hline $\begin{array}{l}\text { Conc., } \\
\text { (ppm) }\end{array}$ & $\begin{array}{c}\text { icorr } \\
\mu \mathrm{A} \mathrm{cm}^{-2}\end{array}$ & $\begin{array}{c}\beta_{a} \\
m V \text { dec }^{-1}\end{array}$ & $\begin{array}{c}\beta_{c} \\
m \text { dec }^{-1}\end{array}$ & CF2 & CF3 & $\begin{array}{c}\text { C.R } \\
\text { (mpy) }\end{array}$ & $\%$ IE \\
\hline Blank & 1670.7 & 58.28 & 158.5 & 2.08 & 3.15 & 68.53 & \\
\hline 100 & 169.8 & 58.7 & 150.1 & 1.90 & 3.24 & 68.14 & 89.8 \\
\hline 150 & 168.4 & 57.7 & 141.8 & 1.94 & 3.04 & 67.58 & 89.9 \\
\hline 200 & 136.6 & 53.48 & 117.3 & 2.02 & 3.02 & 54.8 & 91.78 \\
\hline 250 & 132.2 & 54.59 & 117.7 & 1.91 & 3.09 & 53.06 & 92.10 \\
\hline 300 & 129.6 & 55.48 & 125.3 & 1.96 & 3.50 & 52.30 & 92.2 \\
\hline
\end{tabular}
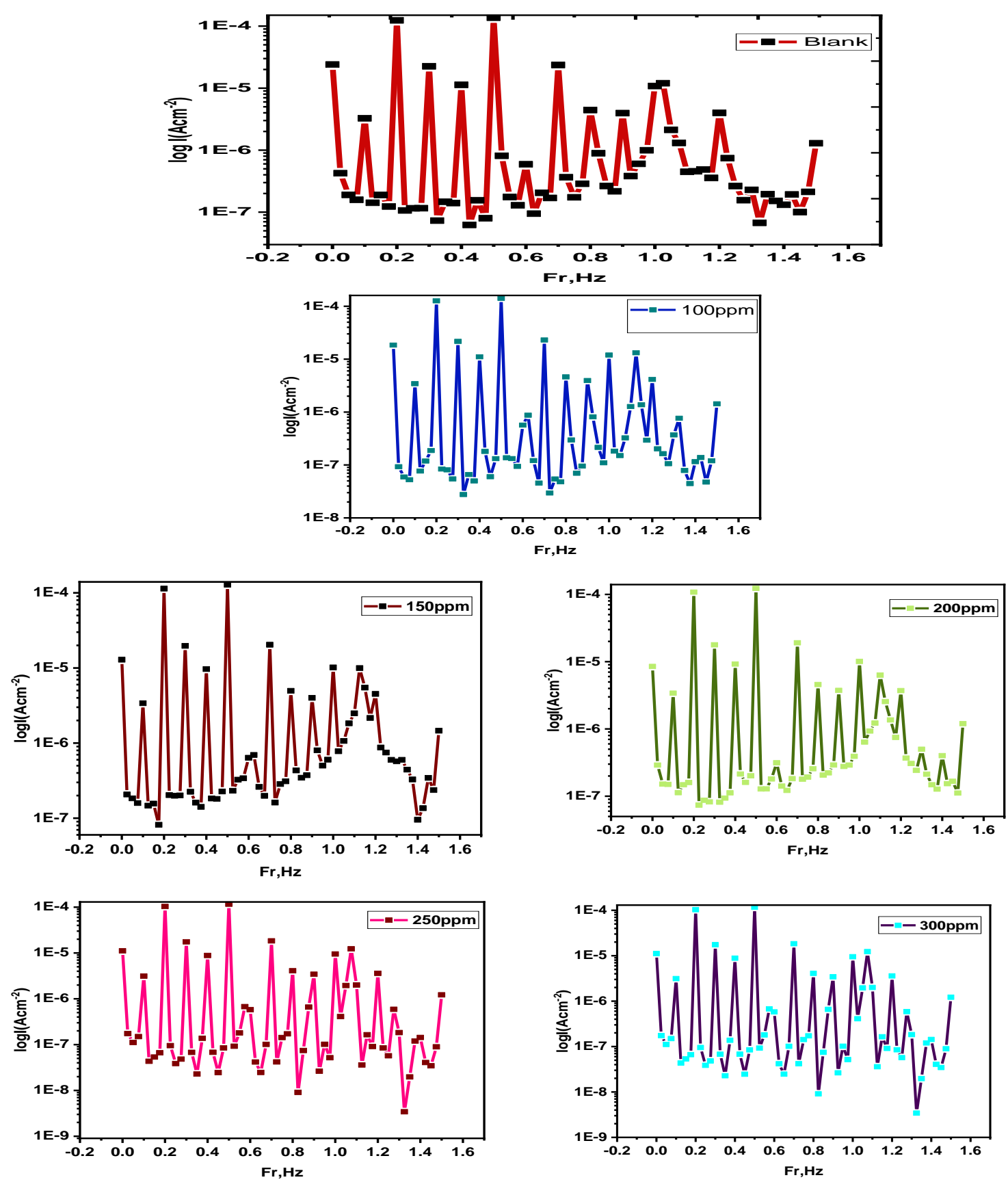

Figure 12. Intermodulation spectra for liquefaction of $\mathrm{Cu}$ in $\mathrm{HNO}_{3}$ attendance and absence of changed doses of rice straw extract at $25^{\circ} \mathrm{C}$. 


\subsection{Surface examinations.}

\subsubsection{AFM analysis.}

Among the tests that are considered highly accurate and used in this research to confirm the results that we obtained before is atomic force microscopy (AFM). In contrast, this scan is accompanied by a constant resolution of arranging nanoscale fractions 1,000 times the optical diffraction limit [71]. Table (8) shows the readings obtained from this survey, where we know the average roughness $\left(\mathrm{S}_{\mathrm{a}}\right)$ and the roughness of the root-mean-square roughness expressed by the symbol $\left(\mathrm{S}_{\mathrm{q}}\right)$, in addition to the value of the maximum height from top to valley and symbolized by P-V value.

Sample

Metal-free

Metal in $2 \mathrm{M} \mathrm{HNO}_{3}$

Metal in $2 \mathrm{M} \mathrm{HNO}_{3}+300 \mathrm{ppm}$ (Rice straw extract)
(3D)
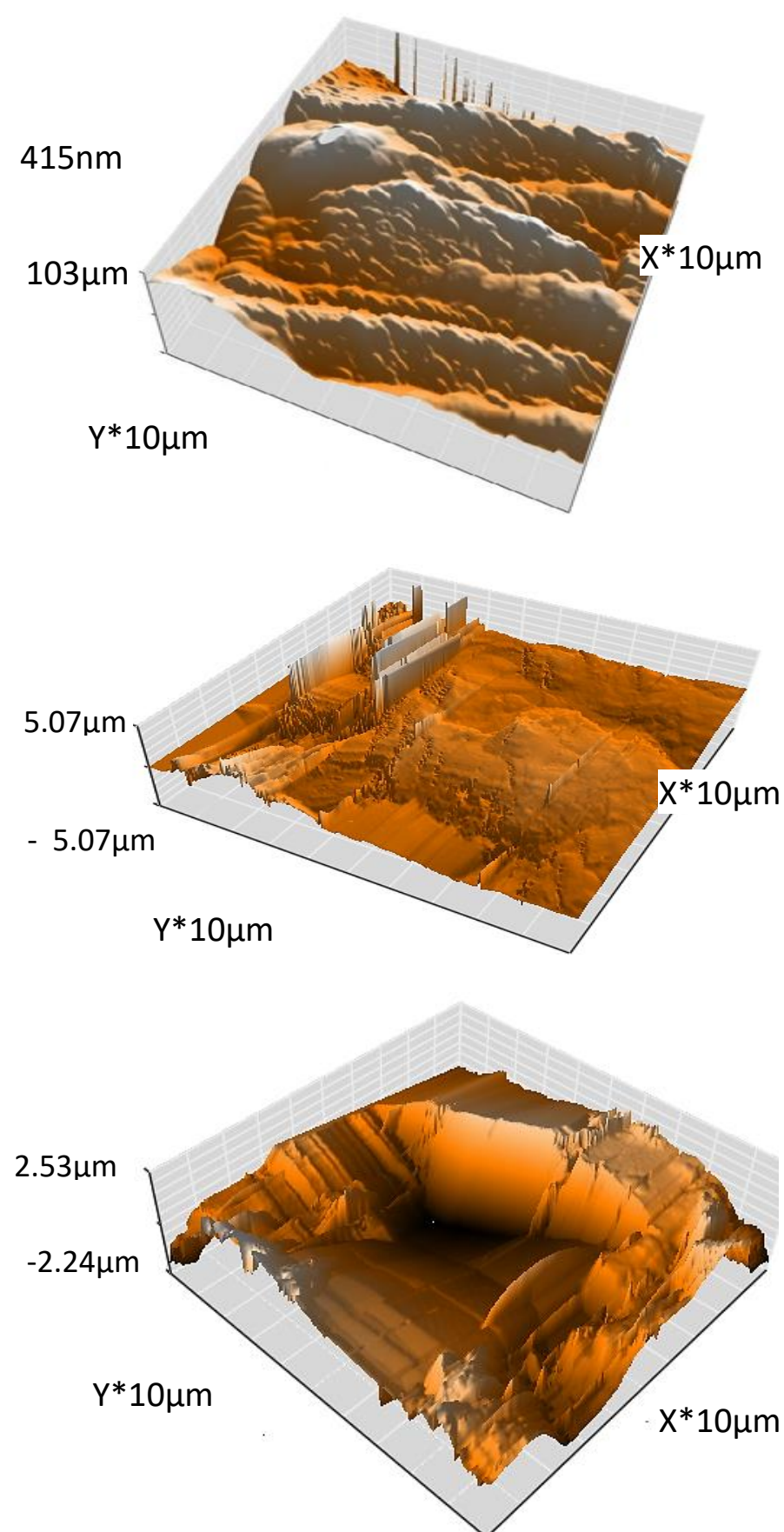

Figure 13. (A) Surface of polished Cu electrode by AFM; (B) Copper surface electrode by AFM after $3 \mathrm{~h}$ dipping in $2 \mathrm{M}$ nitric acid; (C) The surface of $\mathrm{Cu}$ electrode by AFM after $3 \mathrm{~h}$ dipping in $2 \mathrm{M}$ nitric acid solution and 300 ppm rice straw extract. 
Figure 13 demonstrated three $\mathrm{Cu}$ samples. The first sample is only the metal, the second sample is the metal after applying it in $2 \mathrm{M} \mathrm{HCl}$ solution for three hours, and the last sample is the metal after applying it for three hours in $2 \mathrm{M} \mathrm{HNO}_{3}$ solution in the presence of the highest dose of rice straw extract. From the results, we note that the average roughness of the surface decreased in the existence of the highest dose of rice straw extract when dipping $\mathrm{Cu}$ metal in 2 $\mathrm{M}$ of nitric acid from 589.14 to $341.14 \mathrm{~nm}$. This explains that the presence of the highest dose of rice straw extract made the surface smoother, as a result, the creation of a layer on the $\mathrm{Cu}$ surface impeded the uniform corrosion of the surface Figure 13, where the extracted rice straw molecules adsorbed on the surface of copper, reducing the contact between $\mathrm{Cu}$ and nitric acid.

Table 8. Surface copper surface morphology data after dipping for $3 \mathrm{~h}$ in $2 \mathrm{M}$ nitric acid solutions in the presence and absence $300 \mathrm{ppm}$ of rice straw extract was observed in the light of (AFM).

\begin{tabular}{c|c|c|c} 
Samples & $\mathbf{S}_{\mathbf{q},(\mathbf{n m})}$ & $\mathbf{S}_{\mathbf{a}},(\mathbf{n m})$ & Maximum Peak -to- valley Height $(\mathbf{n m})$ \\
\hline Free & 31.622 & 24.87 & 1649.2 \\
\hline blank & 338.15 & 270.68 & 10163 \\
\hline extract & 216.46 & 180.15 & 9680
\end{tabular}

\subsubsection{XPS analysis.}

Inhibitory layer on the surface of the $\mathrm{Cu}$ metal in $2 \mathrm{M} \mathrm{HNO}_{3}$ proves the rice straw exextract's adsorption nature Figure 14 shows the XPS decomposition spectra for each element separately, which are found in the surface layer formed in a solution that controls the presence of the composition of the straw rice extracted. By resorting to published reports on the interpretation of spectral XPS superficial films and The $\mathrm{Cu}$ metal spectra recorded when immersed in a $2 \mathrm{M} \mathrm{HNO}_{3}$ containing the highest dose of rice straw extract (300 ppm) were for $\mathrm{Cl} 2 \mathrm{p}, \mathrm{Cu} 2 \mathrm{p}, \mathrm{O} 1 \mathrm{~s}$, and $\mathrm{C} 1 \mathrm{~s}$. Table 9 shows the binding energies data $(\mathrm{BE}, \mathrm{eV})$ and the same assignment for every peak component [72]. Four different peaks were observed at binding energy values of $284.67,286.6,288.65$, and $289.97 \mathrm{eV}$ for the $\mathrm{C} 1 \mathrm{~s}$ spectra of $\mathrm{Cu}$, which were found in $2 \mathrm{M}$ nitric acid and $300 \mathrm{ppm}$ of rice straw extract. Furthermore, O1s spectra were found in three different peaks at biding energy values of approximately 532.21, 531.72, and $531.02 \mathrm{eV}$.

\subsubsection{FTIR analysis.}

We conducted this study on rice straw extract in two cases: the first case is a solution of $2 \mathrm{M}$ nitric acid, which contains the rice straw extract at the highest dose (300 ppm) in the metal's absence.

Table 9. The determination of binding energies $(\mathrm{eV})$ for the large core lines was noticed for the surface of $\mathrm{Cu}$, which is handled by rice straw extract.

\begin{tabular}{c|c|c}
\multirow{2}{*}{ Core element } & \multicolumn{2}{|c}{ 2MHCl +300ppm of rice straw extract } \\
\cline { 2 - 3 } & $\mathbf{B E}, \mathbf{e V}$ & Assignments \\
\hline \multirow{2}{*}{$\mathrm{C} 1 \mathrm{~s}$} & 284.66 & $\mathrm{C}-\mathrm{H}, \mathrm{C}-\mathrm{C}$, \\
& 286.44 & $\mathrm{C}-\mathrm{O}, \mathrm{C}+-\mathrm{O}$ \\
\hline $\mathrm{Cu} 2 \mathrm{p}$ & 287.5 & $\mathrm{Cu}_{2} \mathrm{O}$ \\
\hline \multirow{2}{*}{$\mathrm{O} 1 \mathrm{~s}$} & 933.14 & \\
& 531.89 & $\mathrm{Cu} 2 \mathrm{O}, \mathrm{Cu}(\mathrm{OH})_{2}$ \\
\hline $\mathrm{N} 1 \mathrm{~s}$ & 532.82 & $\mathrm{Cl} 2 \mathrm{p} 3 / 2$
\end{tabular}


a)

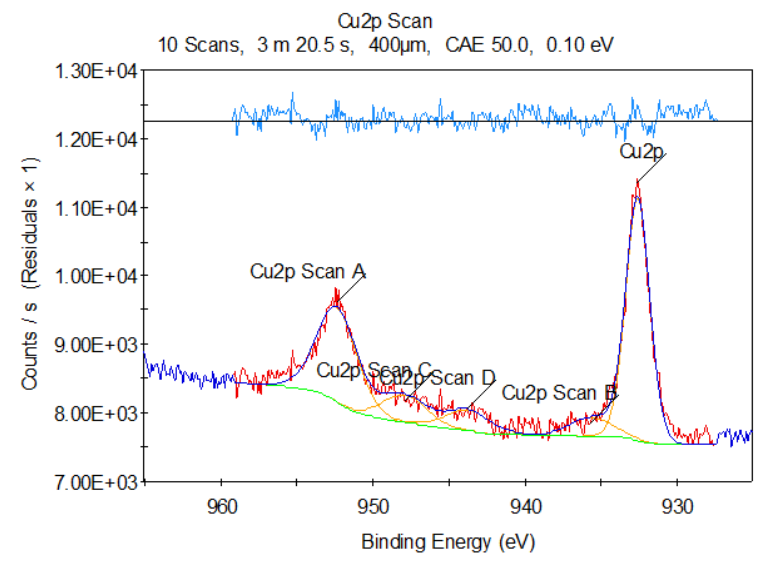

(c)

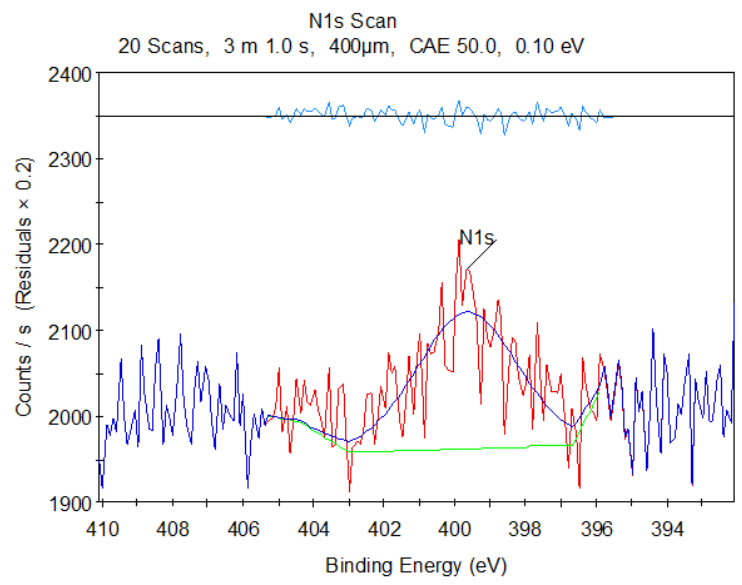

(b)

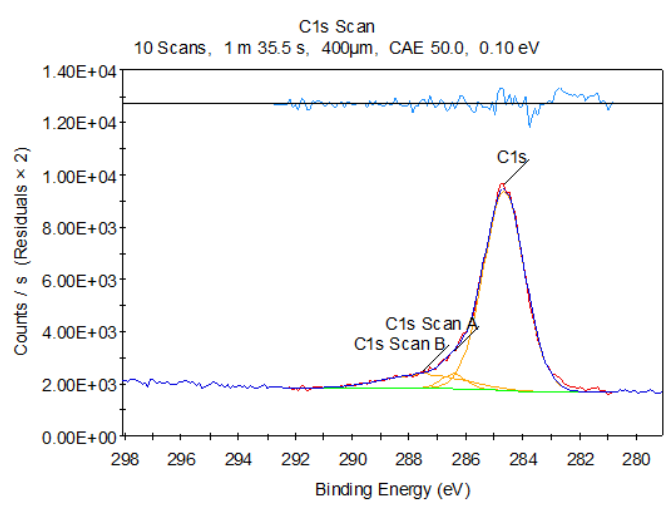

(d)

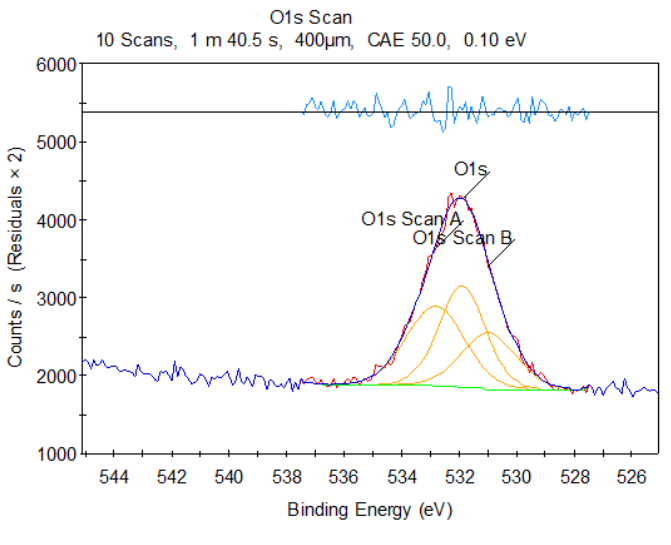

(e)

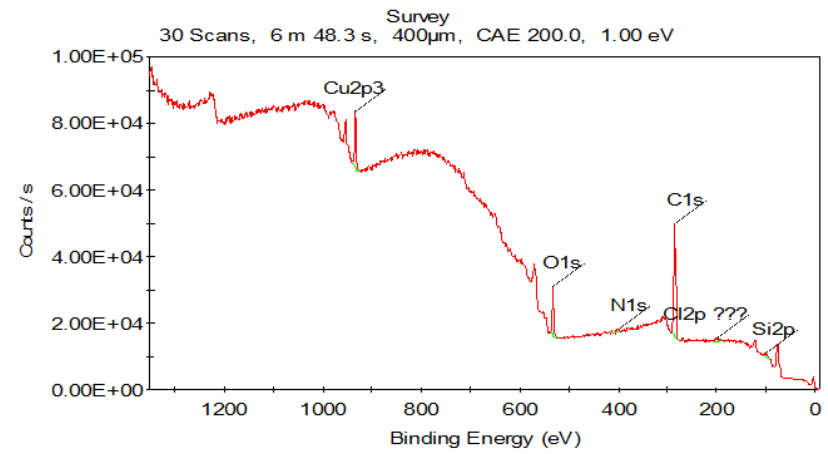

Figure 14. Photoelectric X-rays results from (a) $\mathrm{Cu} 2 \mathrm{p}$; (b) $\mathrm{C} \mathrm{1s}$; (c) $\mathrm{Cl} 2 \mathrm{p}$; (d) O 1s; (e) Scanning elements for $\mathrm{Cu}$ at $2 \mathrm{M}$ nitric acid solutions with $300 \mathrm{ppm}$ from rice straw extract.

The second case is the solution of $2 \mathrm{M}$ nitric acid that contains the rice straw extract at the highest dose after dipping the $\mathrm{Cu}$ metal with it for three hours. Figure 15 shows that the situation did not change in both cases except for a slight displacement between the two forms, indicating that the type of adsorption was physical, as confirmed by free energy calculations according to Table 4.

\subsection{Mechanism of corrosion inhibition.}

This study started by using many different techniques; ML, PP, EIS, EFM, and finally, the methods of surface analysis, all of which confirm the adsorption of rice straw extract molecules on the $\mathrm{Cu}$ surface to form a layer that protects the surface of $\mathrm{Cu}$ in the corrosive medium (2M of nitric acid). 

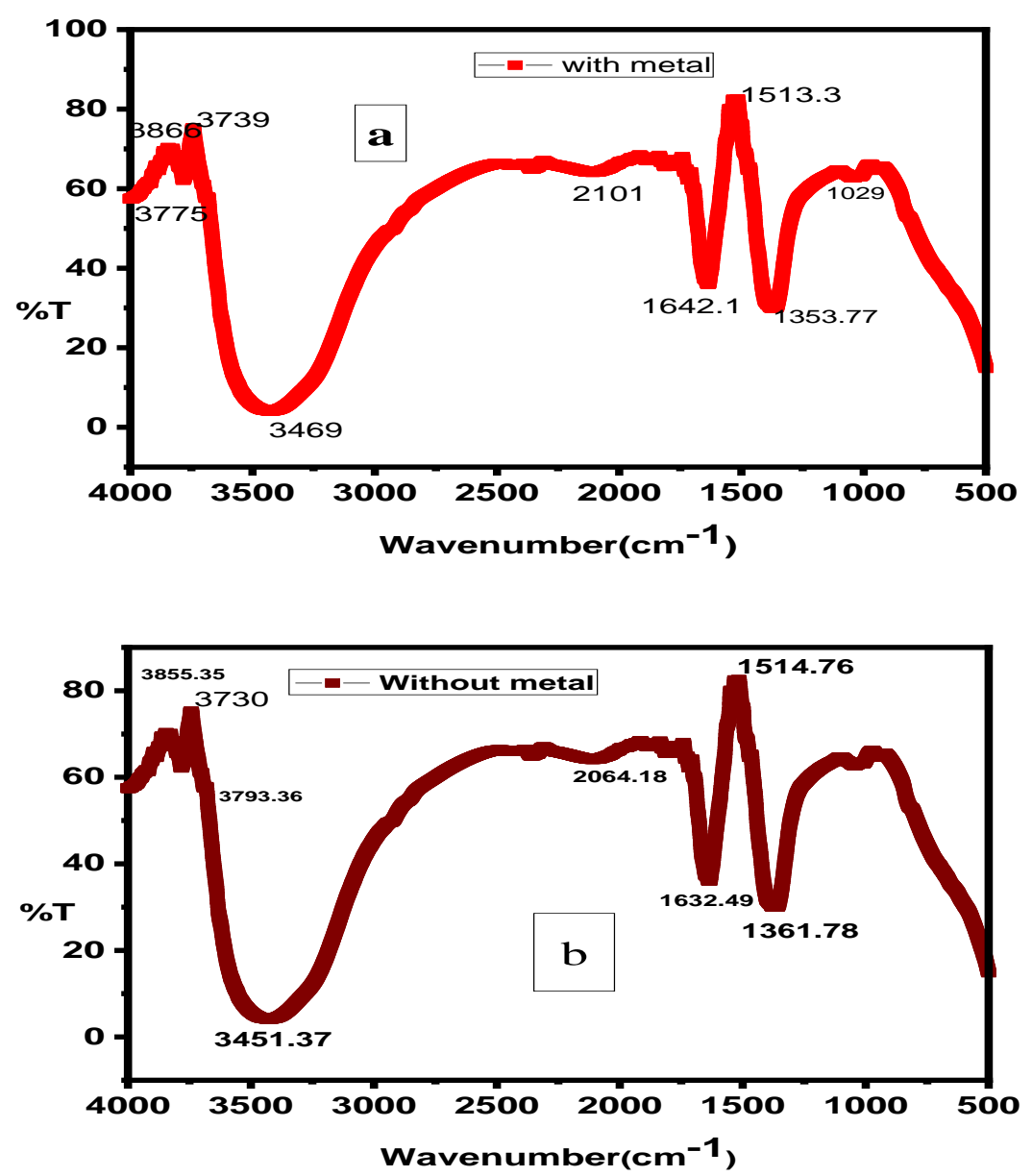

Figure 15. FTIR spectra of: (a) pure rise straw (Red line) and (b) rise straw adsorbed on Cu surface (brown line).

There are three types of reactions that can occur; the electrostatic attractiveness between particles of rice straw extract and the surface of the metal charged, the participation of $\pi$ electrons found in molecules of rice straw extract in the process of coordination, and unshared pair of electrons of extract molecules coordinated with metal atoms [73]. The rice straw extract molecules work as an inhibitor for the $\mathrm{Cu}$ metal. This depends on the presence of oxygen atoms, methoxy groups, and the interaction of $\pi$-electron for aromatic rings with d-electrons that are not shared on the $\mathrm{Cu}$ surface in case of chemical adsorption. The absorption of rice straw molecules onto the metal surface is the first stage in preventing $\mathrm{Cu}$ corrosion in an acidic medium. Through one or more steps, the adsorption process may occur on the surface of the metal. There are two possibilities for adsorption molecules of rice straw to adsorb on the $\mathrm{Cu}$ surface where the inhibitor molecules are distinguished in proton or neutral form. Corrosion of the $\mathrm{Cu}$ metal in $\mathrm{HNO}_{3}$

\section{Conclusions}

The Rice straw extract showed good inhibiting efficacy for $\mathrm{Cu}$ corrosion in $2 \mathrm{M}$ nitric acid. PP indicated that rice straw extract works as a mixed-type inhibitor. By raising the dose of rice straw extract, the effectiveness of the inhibitor increases. Moreover, the extract is inhibited by adsorbing the rice straw extract molecules on the $\mathrm{Cu}$ surface. Adsorption of the extracted molecules comply with the Langmuir and Fluor-Hogan's isotherms, and the adsorption was physical adsorption. The rice straw extract particles' activation energy considers 
more values than the blank activation energy and increases the extract dose. Surface analysis (XPS, FTIR, and AFM) confirmed that the extract layer formed on the $\mathrm{Cu}$ surface, as film prevented the dissolution of metal in the $\mathrm{HNO}_{3}$ solution. All experimental results, which were obtained from the ML method and electrochemical techniques (PP, EIS, and EFM) were consistent with each other.

\section{Funding}

This research received no external funding.

\section{Acknowledgments}

All our gratitude to the anonymous referees for their careful reading of the manuscript and valuable comments helped shape this paper to the present form. We thank all laboratory staff of corrosion chemistry from the University of Mansoura (Egypt) for their kind cooperation.

\section{Conflicts of Interest}

The authors declare that there is no conflict of interest.

\section{References}

1. Verstraeten, S.V.; Aimo, L.; Oteiza, P.I. Al and Pd: molecular mechanisms of brain toxicity. Arch. Toxicol. 2008, 82, 789-802, https://doi.org/10.1007/s00204-008-0345-3.

2. Li, Y.; Cheng, Y. F. Effect of surface finishing on early-stage corrosion of a carbon steel studied by electrochemical and atomic force microscope characterizations, Appl. Surf. Sci. 2016, 366, 95-103, https://doi.org/10.1016/j.apsusc.2016.01.081.

3. Fouda, A.S., El-Ghaffar, M.A.A., Sherif, M.H., El-Habab, A.T. and El-Hossiany, A. Novel Anionic 4-TertOctyl Phenol Ethoxylate Phosphate Surfactant as Corrosion Inhibitor for C-steel in Acidic Media. Protection of Metals and Physical Chemistry of Surfaces 2020, 56, 189-201, https://doi.org/10.1134/S2070205120010086.

4. Baymou, Y.; Bidi, H.; Ebn Touhami, M.; Allam, M.; Rkayae, M.; Belakhmima, R.A. Corrosion Protection for Cast Iron in Sulfamic Acid Solutions and Studies of the Cooperative Effect Between Cationic Surfactant and Acid Counterions. Journal of Bio- and Tribo-Corrosion 2018, 4, https://doi.org/10.1007/s40735-0180127-2.

5. Beda, R. H. B.; Niamien, P. M.; AvoBilé, E. B.; Trokourey, A. Inhibition of Copper Corrosion in 1.0M HCl by Caffeine: Experimental and DFT Studies, Advances in Chemistry, 2017, 217, 6975248-6975258, https://doi.org/10.1155/2017/6975248.

6. Fouda, A.S., El-Dossoki, F.I., El-Hossiany, A. and Sello, E.A. Adsorption and Anticorrosion Behavior of Expired Meloxicam on Mild Steel in Hydrochloric Acid Solution. Surface Engineering and Applied Electrochemistry 2020, 56, 491-500.

7. Ardakani, E.K.; Kowsari, E.; Ehsani, A. Imidazolium derived polymeric ionic liquid as a green inhibitor for corrosion inhibition of mild steel in $1.0 \mathrm{M} \mathrm{HCl}$ : Experimental and computational study. Colloids and Surfaces A: Physicochemical and Engineering Aspects 2020, 564, https://doi.org/10.1016/j.colsurfa.2019.124195.

8. Gece, G.; Bilgic, S. Quantum chemical study of some cyclic nitrogen compounds as corrosion inhibitors of steel in NaCl media, Corrosion Science 2009, 51, 1876-1878, https://doi.org/10.1016/j.corsci.2009.04.003.

9. Roque, J. M.; Pandiyan, T.; Cruz, J.; Garcl'a-Ochoa, E. DFT and electrochemical studies of tris (benzimidazole-2-ylmethyl) amine as an efficient corrosion inhibitor for carbon steel surface, Corrosion Science 2008, 50, 614-624, https://doi.org/10.1016/j.corsci.2007.11.012.

10. Hegazy, M.A. Novel cationic surfactant based on triazole as a corrosion inhibitor for carbon steel in phosphoric acid produced by dihydrate wet process, J. Mol. Liq. 2015, 208, 227-236, https://doi.org/10.1016/j.molliq.2015.04.042. 
11. Ahamad, I.; Prasad, R.; Quraishi, M. A. Inhibition of mild steel corrosion in acid solution by Pheniramine drug: an experimental and theoretical study, Corros. Sci. 2010, 52, 3033-3041, https://doi.org/10.1016/j.corsci.2010.05.022.

12. Aoun, S. B.; Messali, M. Microwave-assisted synthesis of green inhibitor for carbon steel acid corrosion. Int. J. Electrochem. Sci. 2018, 13, 3757 - 3776, https://doi.org/10.20964/2018.04.55.

13. Wenwu Li; Zhe Zhang; Ying Zhai; Le Ruan; Weipeng Zhang; Ling Wu. Electrochemical and Computational Studies of Proline and Captopril as Corrosion Inhibitors on Carbon Steel in a Phase Change Material Solution. Int. J. Electrochem. Sci. 2020, 15, 722 - 739, https://doi.org/10.20964/2020.01.63.

14. Lavanya, D.K., Priya, F.V., Vijaya, D.P. Green Approach to Corrosion Inhibition of Mild Steel in Hydrochloric Acid by 1- [Morpholin-4-yl(thiophen-2-yl)methyl]thiourea. J Fail. Anal. and Preven. 2020, https://doi.org/10.1007/s11668-020-00850-9.

15. Abdallah Y.M.; Shalabi, K.; Bayoumy, N.M. Eco-friendly synthesis, biological activity and evaluation of some new pyridopyrimidinone derivatives as corrosion inhibitors for API 5L X52 carbon steel in 5\% sulfamic acid medium, J. Mol. Struct. 2018, 1171, 658-671, https://doi.org/10.1016/j.molstruc.2018.06.045.

16. Fouda, A.S.; El-Awady, G.Y.; El Behairy, W.T. Prosopis juliflora Plant Extract as Potential Corrosion Inhibitor for Low-Carbon Steel in $1 \mathrm{M} \mathrm{HCl} \mathrm{Solution.} \mathrm{Journal} \mathrm{of} \mathrm{Bio-} \mathrm{and} \mathrm{Tribo-Corrosion} \mathrm{2017,} \mathrm{4,}$ https://doi.org/10.1007/s40735-017-0124-x.

17. Abdel Rehim, S.S; Hazzazi, O. A.; Amin, M.A.; Khaled, K.F. On the corrosion inhibition of low CS in concentrated sulphuric acid solutions. Part I: Chemical and electrochemical (AC and DC) studies. Corros. Sci. 2008, 50, 2258-2271, https://doi.org/10.1016/j.corsci.2008.06.005.

18. Ramana, P.V., Suryanarayana, B.S., Ravindranath, L.K., Rao, S.B. and Ramadas, S.R.. Electrochemical behavior of 3-amino-1-phenyl-4-substituted benzene-azo) pyrazolin-5ones, Indian Journal of Chemistry, Section A: Inorganic, Physical, Theoretical \& Analytical 1990, 29, 864-866, http://nopr.niscair.res.in/handle/123456789/46491.

19. Shimizu, K.; Lasia, A.; Boily, J.F. Electrochemical impedance study of the hematite/water interfaces. Langmuir 2012, 28, 7914-7920, https://doi.org/10.1021/la300829c.

20. Bosch, R.W.; Hubrecht, J.; Bogaerts, W.F.; Syrett, B.C. Electrochemical Frequency Modulation: A New Electrochemical Technique for Online Corrosion Monitoring. Corrosion 2001, 57, 60-70, https://doi.org/10.5006/1.3290331.

21. El-Askalany, A.H.; Mostafa,S. I.; Shalabi, K.; Eid, A.M.; Shaabana, S. Novel tetrazole-based symmetrical diselenides as corrosion inhibitors for $\mathrm{N} 80$ carbon steel in $1 \mathrm{M} \mathrm{HCl}$ solutions: Experimental and theoretical studies, J. Mol. Liq. 2016, 223, 497-508, https://doi.org/10.1016/j.molliq.2016.08.088.

22. Fouda, A.S.; Abdel Azeem, M.; Mohamed, S.A., El-Hossiany, A.; El-Desouky, E. Corrosion Inhibition and Adsorption Behavior of Nerium Oleander Extract on Carbon Steel in Hydrochloric Acid Solution. Int. J. Electrochem. Sci. 2019, 14, 3932 - 3948, https://doi.org/10.20964/2019.04.44.

23. Bentiss, F.; Bouanis, M., Mernari, B.; Traisnel, M.; Vezin, H.; Lagrenee, M. Understanding the adsorption of 4H-1,2,4- triazole derivatives on mild steel surface in molar hydrochloricacid. Appl. Surf. Sci. 2007, 253, 3696-3704, https://doi.org/10.1016/j.apsusc.2006.08.001.

24. Elkadi, L.; Mernari, B.; Traisnel, M.; Bentiss, F.; Lagrenee, M. The inhibition action of 3,6-bis (2methoxyphenyl)-1, 2-dihydro-1, 2, 4, 5-tetrazine on the corrosion of mild steel in acidic media. Corrosion Science 2000, 42, 703-719, https://doi.org/10.1016/S0010-938X(99)00101-8.

25. Singh, A.K.; Quraishi, M.A. Investigation of the effect of disulfiram on corrosion of mild steel in hydrochloric acid solution. Corrosion Science 2011, 53, 1288-1297, https://doi.org/10.1016/j.corsci.2011.01.002.

26. Francis, O. N.; Israel O. O.; Osarolube, E. Acidic Corrosion Inhibition Mechanism of AlAlloy Using Green Inhibitors. American Journal of Materials Science 2018, 8, 45-50, https://doi.org/10.5923/j.materials.20180803.01.

27. Raja, P.B.; Sethuraman, M. G. Natural products as corrosion inhibitor for metals in corrosive media-A review. Materials Letters 2008, 62, 113-116, https://doi.org/10.1016/j.matlet.2007.04.079.

28. Shyamala, M.; Arulanantham, A. A comparative study on the inhibitory action of some green inhibitors on the corrosion of mild steel in nitrric acid medium. Malaysian Journal of Analytical Sciences 2017, 21,346 355, https://doi.org/10.17576/mjas-2017-2102-09.

29. Khaled, K.F. Evaluation of electrochemical frequency modulation as a new technique for monitoring corrosion and corrosion inhibition of carbon steel in perchloric acid using hydrazine carbodithioic acid derivatives. Journal of applied electrochemistry 2009, 39, 429-438, https://doi.org/10.1007/s10800-0089688-y. 
30. Shyamala, M., Kasthuri, P. K. The Inhibitory Action of the Extracts of Adathoda vasica, Eclipta alba, and Centella Asiatica on the Corrosion of Mild Steel in Nitric Acid Medium: A Comparative Study. International Journal of Corrosion 2012, 2012, 852827-852827, https://doi.org/10.1155/2012/852827.

31. Singh, A.; Ebenso, E. E.; Quraishi, M. A. Corrosion Inhibition of Carbon Steel in HCl Solution by Some Plant Extracts. Int. national journal of corrosion 2012, 2012, 897430-897442, https://doi.org/10.1155/2012/897430.

32. Nazeer,A. A.; Shalabi, K.; Fouda,A. S. Corrosion inhibition of carbon steel by Roselle extract in nitric acid solution: electrochemical and surface study. Res ChemIntermed 2015, 41, 4833-4850, https://doi.org/10.1007/s11164-014-1570-4.

33. Deyab, M.A.; Osman, M.M.; Elkholya, A. E.; El-TaibHeakal, F. Green approach towards corrosion inhibition of carbon steel in produced oilfield water using lemongrass extract. RSC Adv. 2017, 7, 45241-45251, https://doi.org/10.1039/c7ra07979f.

34. Fouda, A. S.; El-shereafy, E. E.; Hathoot, A. A.; El-bahrawi, N. M. Corrosion Inhibition of Al by Cerumium rubrum Extraction Hydrochloric Acid Environment. Journal of Bio- and Tribo-Corrosion 2020, 6, 37-53, https://doi.org/10.1007/s40735-020-0330-9.

35. Marciales, A.; Haile, T.; Ahvazi, B.; Ngo,T.; John W. Performance of green corrosion inhibitors from biomass in acidic media. Corrosion Reviews 2018, 36, 239-266, https://doi.org/10.1515/corrrev-2017-0094.

36. Popoola, L.T. Progress on pharmaceutical drugs, plant extracts and ionic liquids as corrosion inhibitors. Heliyon 2019, 5, e0114, https://doi.org/10.1016/j.heliyon.2019.e01143

37. Al Hasan, N.H.J.; Alaradi, H.J.; Al Mansor, Z.A.K.; Al Shadood, A.H.J. The dual effect of stem extract of Brahmi (Bacopamonnieri) and Henna as a green corrosion inhibitor for low carbon steel in $0.5 \mathrm{M} \mathrm{NaOH}$ solution. Case Stud. Constr. Mater. 2019, 11, e00300. https://doi.org/10.1016/j.cscm.2019.e00300.

38. Pradipta, I.; Kong, D.; Tan, J.B.L. Natural organic antioxidants from green tea inhibit corrosion of steel reinforcing bars embedded in mortar. Constr. Build. Mater. 2019, 227, 117058, https://doi.org/10.1016/j.conbuildmat.2019.117058.

39. Emori, W.; Zhang, R.-H.; Okafor, P.C.; Zheng, X.-W.; He, T.; Wei, K.; Lin, X.-Z.; Cheng, C.-R. Adsorption and corrosion inhibition performance of multi-phytoconstituents from Dioscorea septemloba on carbon steel in acidic media: Characterization, experimental and theoretical studies. Colloids Surf. Physicochem. Eng. Asp. 2020, 590, 124534. https://doi.org/10.1016/j.colsurfa.2020.124534.

40. Akinbulumo, O.A.; Odejobi, O.J.; Odekanle, E.L. Thermodynamics and adsorption study of the corrosion inhibition of mild steel by Euphorbia heterophylla L. extract in $1.5 \mathrm{M} \mathrm{HCl}$. Results Mater. 2020, 5, 100074, https://doi.org/10.1016/j.rinma.2020.100074.

41. Anyiam, C.K.; Ogbobe, O.; Oguzie, E.E.; Madufor, I.C.; Nwanonenyi, S.C.; Onuegbu, G.C.; Obasi, H.C.; Chidiebere, M.A. Corrosion inhibition of galvanized steel in hydrochloric acid medium by a physically modified starch. SN Appl. Sci. 2020, 2, 520, https://doi.org/10.1007/s42452-020-2322-2.

42. Mohammed, A.R.I.; Solomon, M.M.; Haruna, K.; Umoren, S.A.; Saleh, T.A. Evaluation of the corrosion inhibition efficacy of Cola acuminata extract for low carbon steel in simulated acid pickling environment. Environmental Science and Pollution Research 2020, 27, 34270-34288, https://doi.org/10.1007/s11356-020-09636-w.

43. Abuzaid, H.; Amin, E., Moawad, A.; Abdelmohsen, U. R.; Hetta, M.; Mohammed, R. Liquid chromatography high-resolution mass spectrometry analysis, phytochemical and biological study of two aizoaceae plants: A new kaempferol derivative from Trianthema portulacastrum L. Pharmacognosy Research, 2020, 12, 212218.

44. Haldhar R.; Prasad D.; Bahadur, I.; Dagdag, O.; Berisha, A. Evaluation of Gloriosa superba seeds extract as corrosion inhibition for low carbon steel in sulfuric acidic medium: A combined experimental and computational studies. Journal of Molecular Liquids 2021, 323, 114958-114967, https://doi.org/10.1016/j.molliq.2020.114958.

45. Vorobyova, V.; Skiba, M. Peach Pomace Extract as Efficient Sustainable Inhibitor for Carbon Steel Against Chloride-Induced Corrosion. Journal of Bio-and Tribo-Corrosion 2021, 7, 1-11, https://doi.org/ 10.1007/s40735-020-00450-y.

46. Peñaloza, E.; Holandino, C.; Scherr, C.; de Araujo, P.I.; Borges, R.M.; Urech, K.; Baumgartner, S.; Garrett, R. Comprehensive Metabolome Analysis of Fermented Aqueous Extracts of Viscum album L. by Liquid Chromatography- High Resolution Tandem Mass Spectrometry. Molecules 2020, 25, 4006-4020, https://doi.org/10.3390/molecules25174006. 
47. Agbaffa, E.B.; Akintemi, E.O.; Uduak, E.A.; Oyeneyin, O.E. Corrosion inhibition potential of the methanolic crude extract of Mimosa pudica leaves for mild steel in $1 \mathrm{M}$ hydrochloric acid solution by weight loss method. Science Letters 2021, 15, 23-42, https://doi.org/10.24191/sl.v15i1.11791.

48. Elabbasy, H.M.; Zidan, S.M.; Fouda, A.S. Inhibitive behavior of ambrosia maritima extract as an eco-friendly corrosion inhibitor for carbon steel in $1 \mathrm{M} \mathrm{HCl}$. Zastita Materijala 2019, 60, 129-146, https://doi.org/10.5937/zasmat1902129E.

49. Fouda, A.S.; Abd El-Maksoud, S.A.; El-Hossiany, A.; Ibrahim, A. Corrosion Protection of Stainless Steel 201 in Acidic Media using Novel Hydrazine Derivatives as Corrosion Inhibitors. Int. J. Electrochem. Sci. 2019, 14, 2187-2207, https://doi.org/10.20964/2019.03.15.

50. Fouda, A. S.; Al-Hazmi, N. E.; El-Zehry, H. H.; El-Hossainy, A. Electrochemical and Surface Characterization of Chondria Macrocarpa Extract (CME) as Save Corrosion Inhibitor for Aluminum in 1M HCl Medium. Journal of Applicable Chemistry 2020, 9, 362-381.

51. Raghavendra, N.; Hublikar, L.V.; Patil, S.M.; Ganiger, P.J.; Bhinge, A.S. Efficiency of sapota leaf extract against aluminum corrosion in a $3 \mathrm{M}$ sodium hydroxide hostile fluid atmosphere: a green and sustainable approach. Bulletin of Materials Science 2019, 42, https://doi.org/10.1007/s12034-019-1922-1.

52. Fouda, A.S.; Rashwan, S.; Kamel, M.M.; Arman, N.M. Adsorption, and Inhibition Behavior of Avicennia Marina for Zn Metal in Hydrochloric Acid Solution. International Journal of Electrochemical Science 2017, 12, 11789-11804, https://doi.org/10.20964/2017.12.95.

53. Fouda, A.S.; Abd El-Maksoud, S.A.; El-Hossiany, A.; Ibrahim, A. Effectiveness of Some Organic Compounds as Corrosion Inhibitors for Stainless Steel 201 in $1 \mathrm{M} \mathrm{HCl}$ : Experimental and Theoretical Studies. Int. J. Electrochem. Sci. 2018, 13, 9826 - 9846, https://doi.org/10.20964/2018.10.36.

54. Ibrahim, M.B.; Sulaiman, Z.; Usman, B.; Ibrahim, M.A. Effect of Henna Leaves on the Corrosion Inhibition of Tin in Acidic and Alkaline Media. World Journal of Applied Chemistry 2019, 4, 54-51, https://doi.org/10.11648/j.wjac.20190404.11.

55. Fouda, A.S.; Abdel Azeem, M.; Mohamed, S.A., El-Hossiany, A.; El-Desouky, E. Corrosion Inhibition and Adsorption Behavior of Nerium Oleander Extract on Carbon Steel in Hydrochloric Acid Solution. Int. J. Electrochem. Sci. 2019, 14, 3932 - 3948, https://doi.org/10.20964/2019.04.44.

56. Zhang, S.; Hou, L.; Du, H.; Wei, H.; Liu, B.; Wei, Y. A study on the interaction between chloride ions and CO2 towards carbon steel corrosion. Corrosion Science 2020, 167, 108531-108541, https://doi.org/10.1016/j.corsci.2020.108531.

57. Fouda, A.S.; Killa, H.M.; Farouk, A.; Salem, A.M. Calicotome Extract as a Friendly Corrosion Inhibitor for Carbon Steel in Polluted $\mathrm{NaCl}$ Solution: Chemical and Electrochemical Studies. Egyptian Journal of Chemistry 2019, 62, 1879-1894, https://doi.org/10.21608/EJCHEM.2019.7656.1649.

58. Fouda, A.S.; Eissa, M.; El-Hossiany, A.; Ciprofloxacin as Eco-Friendly Corrosion Inhibitor for Carbon Steel in Hydrochloric Acid Solution. Int. J. Electrochem. Sci. 2018, 13, $11096 \quad-\quad 11112$, https://doi.org/10.20964/2018.11.86.

59. Fouda, A.S.; Rashwan, S.; El-Hossiany, A.; El-Morsy, F. E. Corrosion Inhibition of Zinc in Hydrochloric Acid Solution using some organic compounds as Eco-friendly Inhibitors. JCBPS. 2019, 9, 001-024, https://doi.org/10.24214/jcbps.A.9.1.00124.

60. Hsissou, R.; Abbout, S.; Berisha, A.; Berradi, M.; Assouag, M.; Hajjaji, N.; Elharfi, A. Experimental, DFT and molecular dynamics simulation on the inhibition performance of the DGDCBA epoxy polymer against the corrosion of the E24 carbon steel in $1.0 \mathrm{M} \mathrm{HCl}$ solution. Journal of Molecular Structure 2019, 1182, 340351, https://doi.org/10.1016/j.molstruc.2018.12.030.

61. Motawea, M. M.; El-Hossiany, A.; Fouda, A.S. Corrosion Control of Copper in Nitric Acid Solution using Chenopodium Extract. Int. J. Electrochem. Sci. 2019, 14, 1372 - 1387, https://doi.org/10.20964/2019.02.29.

62. Soltani, N.; Tavakkoli, N.; Attaran, A.; Karimi, B.; Khayatkashani, M. Inhibitory effect of Pistacia khinjuk aerial part extract for carbon steel corrosion in sulfuric acid and hydrochloric acid solutions. Chemical Papers 2020, 74, 1799-1815, https://doi.org/10.1007/s11696-019-01026-y.

63. Abdel-Gaber, A.M., Rahal, H.T. and Beqai, F.T. Eucalyptus leaf extract as a eco-friendly corrosion inhibitor for mild steel in sulfuric and phosphoric acid solutions. International Journal of Industrial Chemistry, 2020, 1-10, https://doi.org/10.1007/s40090-020-00207-z.

64. Haldhar, R., Prasad, D. and Bhardwaj, N. Extraction and experimental studies of Citrus aurantifolia as an economical and green corrosion inhibitor for mild steel in acidic media. Journal of Adhesion Science and Technology 2019, 33, 1169-1183, https://doi.org/10.1080/01694243.2019.1585030. 
65. Fouda, A.S.; Abd El-Maksoud, S.A.; El-Hossiany, A.; Ibrahim, A. Evolution of the Corrosion-inhibiting Efficiency of Novel Hydrazine Derivatives against Corrosion of Stainless Steel 201 in Acidic Medium. Int. J. Electrochem. Sci. 2019, 14, 6045 - 6064, https://doi.org/10.20964/2019.07.65.

66. Fouda, A. S.; El-shereafy, E. E.; Hathoot, A. A.; El-bahrawi, N.M. Corrosion Inhibition of Al by Cerumium rubrum Extraction Hydrochloric Acid Environment. Journal of Bio- and Tribo-Corrosion 2020, 1, 6-37, https://doi.org/10.1007/s40735-020-0330-9.

67. Caigman, G.A., Metcalf, S.K., Holt, E.M., Thiophene substituted dihydropyridines. J. Chem. Cryst., 2000, 30, 415-422.

68. Gadow, H.S.; Thoraya A. F.; Eldesoky, A.M. Experimental and theoretical investigations for some spiro pyrazoles derivatives as corrosion inhibitors for copper in $2 \mathrm{M} \mathrm{HNO}_{3}$ solutions. Journal of Molecular Liquids 2019, 294, 111614-111635, https://doi.org/10.1016/j.molliq.2019.111614.

69. Shalabi, K.; Abdallah, Y.M.; Fouda, A.S.; Corrosion inhibition of Al in $0.5 \mathrm{MHCl}$ solutions containing phenyl sulfonylacetophenoneazo derivatives. Res. Chem. Internet. 2015, 41, 4687-4711, https://doi.org/10.1007/s11164-014-1561-5.

70. Fouda, A.S.; Nazeer, A. A.; Saber, A. Electrochemical adsorption properties and inhibition of zinc corrosion by two chromones in sulfuric acid solutions. J. Korean Chem. Soc. 2014, 58, 160-168, https://doi.org/10.5012/jkcs.2014.58.2.160.

71. Murmu, M., Sahara,S. K.; Bhaumick, P.; Chandr Murmu, N.; Hirani, H.; Banerjee, P. Corrosion inhibition property of azomethine functionalized triazole derivatives in $1 \mathrm{~mol} \mathrm{~L}-1 \mathrm{HCl}$ medium for mild steel: Experimental and theoretical exploration. Journal of Molecular Liquids 2020, 313, 113508-113515, https://doi.org/10.1016/j.molliq.2020.113508.

72. Hashim, N. N.; Anouar, E.; Kassim, K.; Zaki, H.M.; Alharthi, A.I.; Embong, Z. XPS and DFT investigations of corrosion inhibition of substituted benzylidene Schiff bases on mild steel in hydrochloric acid. Appl. Surf. Sci. 2019, 476, 861-877, https://doi.org/10.1016/j.apsusc.2019.01.149.

73. Fouda, A. S.; Abousalem, A. S.; EL-Ewady, G. Y. Mitigation of corrosion of carbon steel in acidic solutions using an aqueous extract of Tilia cordata as a green corrosion inhibitor. Int $J$ Ind Chem 2017, 8, 61-73, https://doi.org/10.1007/s40090-016-0102-z. 